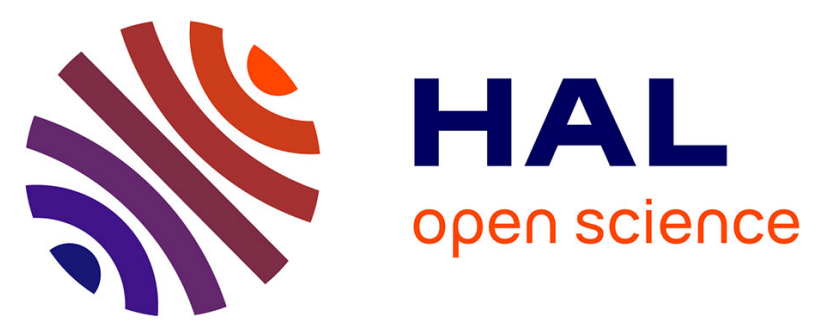

\title{
Fate of trace organic compounds in the hyporheic zone: influence of retardation, the benthic bio-layer and organic carbon
}

\author{
Jonas Schaper, Malte Posselt, Camille Bouchez, Anna Jaeger, Gunnar \\ Nuetzmann, Anke Putschew, Gabriel Singer, Jörg Lewandowski
}

\section{To cite this version:}

Jonas Schaper, Malte Posselt, Camille Bouchez, Anna Jaeger, Gunnar Nuetzmann, et al.. Fate of trace organic compounds in the hyporheic zone: influence of retardation, the benthic bio-layer and organic carbon. Environmental Science and Technology, 2019, 53 (8), pp.4224-4234. 10.1021/acs.est.8b06231 . insu-02082924

\section{HAL Id: insu-02082924 https://hal-insu.archives-ouvertes.fr/insu-02082924}

Submitted on 28 Mar 2019

HAL is a multi-disciplinary open access archive for the deposit and dissemination of scientific research documents, whether they are published or not. The documents may come from teaching and research institutions in France or abroad, or from public or private research centers.
L'archive ouverte pluridisciplinaire HAL, est destinée au dépôt et à la diffusion de documents scientifiques de niveau recherche, publiés ou non, émanant des établissements d'enseignement et de recherche français ou étrangers, des laboratoires publics ou privés. 
Subscriber access provided by SCD Université de Rennes1 | SCD de l'Université de Rennes 1

\title{
Environmental Processes
}

\author{
Fate of trace organic compounds in the hyporheic zone: \\ influence of retardation, the benthic bio-layer and organic carbon \\ Jonas Schaper, Malte Posselt, Camille Bouchez, Anna Jaeger, Gunnar \\ Nützmann, Anke Putschew, Gabriel Singer, and Jörg Lewandowski \\ Environ. Sci. Technol., Just Accepted Manuscript • Publication Date (Web): 24 Mar 2019 \\ Downloaded from http://pubs.acs.org on March 28, 2019
}

\section{Just Accepted}

"Just Accepted" manuscripts have been peer-reviewed and accepted for publication. They are posted
online prior to technical editing, formatting for publication and author proofing. The American Chemical
Society provides "Just Accepted" as a service to the research community to expedite the dissemination
of scientific material as soon as possible after acceptance. "Just Accepted" manuscripts appear in
full in PDF format accompanied by an HTML abstract. "Just Accepted" manuscripts have been fully
peer reviewed, but should not be considered the official version of record. They are citable by the
Digital Object Identifier (DOIB). "Just Accepted" is an optional service offered to authors. Therefore,
the "Just Accepted" Web site may not include all articles that will be published in the journal. After
a manuscript is technically edited and formatted, it will be removed from the "Just Accepted" Web
site and published as an ASAP article. Note that technical editing may introduce minor changes
to the manuscript text and/or graphics which could affect content, and all legal disclaimers and
ethical guidelines that apply to the journal pertain. ACS cannot be held responsible for errors or
consequences arising from the use of information contained in these "Just Accepted" manuscripts. 
1 Fate of trace organic compounds in the hyporheic zone: influence of 2 retardation, the benthic bio-layer and organic carbon

3 Jonas L. Schaper ${ }^{1,2 *}$, Malte Posselt, ${ }^{3}$ Camille Bouchez, ${ }^{4}$ AnNa Jaeger, ${ }^{1,5}$ GunNar

4 Nuetzmann,,${ }^{1,5}$ AnKe Putschew, ${ }^{2}$ Gabriel Singer, ${ }^{1}$ AND JoERg Lewandowski ${ }^{1,5}$

$5{ }^{1}$ Leibniz-Institute of Freshwater Ecology and Inland Fisheries, Department Ecohydrology, Müggelseedamm 310,

$6 \quad 12587$ Berlin, Germany

72 Technische Universität Berlin, Chair of Water Quality Engineering, Strasse des 17. Juni 135, 10623 Berlin,

8 Germany

$9{ }^{3}$ Department of Environmental Science and Analytical Chemistry (ACES), Stockholm University, Stockholm,

10 Sweden

$11 \quad{ }^{4}$ Univ Rennes, CNRS, Géosciences Rennes, UMR 6118, 35000 Rennes, France

$12{ }^{5}$ Humboldt University Berlin, Geography Department, Rudower Chaussee 16, 12489 Berlin, Germany

13

14

$15 *$ corresponding author; schaper@igb-berlin.de, Leibniz-Institute of Freshwater Ecology and Inland Fisheries,

16 Department Ecohydrology, Müggelseedamm 310, 12587 Berlin, Germany

17 


\section{Abstract}

19 The fate of 28 trace organic compounds (TrOCs) was investigated in the hyporheic zone (HZ) of an urban

20 lowland river in Berlin, Germany. Water samples were collected hourly over $17 \mathrm{~h}$ in the river and in three 21 depths in the HZ using minipoint samplers. The four relatively variable time series were subsequently

22 used to calculate first-order removal rates and retardation coefficients via a one-dimensional reactive 23 transport model. Reversible sorption processes led to substantial retardation of many TrOCs along the 24 investigated hyporheic flow path. Some TrOCs such as dihydroxy-carbamazepine, O25 desmethylvenlafaxine and venlafaxine were found to be stable in the HZ. Others were readily removed 26 with half-lives in the first $10 \mathrm{~cm}$ of the $\mathrm{HZ}$ ranging from $0.1 \pm 0.01 \mathrm{~h}$ for iopromide to $3.3 \pm 0.3 \mathrm{~h}$ for

27 tramadol. Removal rate constants of the majority of reactive TrOCs were highest in the first $10 \mathrm{~cm}$ of the $28 \mathrm{HZ}$, where removal of biodegradable dissolved organic matter was also highest. Because conditions were 29 oxic along the top $30 \mathrm{~cm}$ of the investigated flow path we attribute this finding to the high microbial 30 activity typically associated with the shallow HZ. Frequent and short vertical hyporheic exchange flows 31 could therefore be more important for reach-scale TrOC removal than long, lateral hyporheic flow paths. 


\section{Keywords}

33 Pharmaceuticals, metformin, guanylurea, urban water cycle, reactive transport modeling

\section{$34 \quad$ TOC Art}

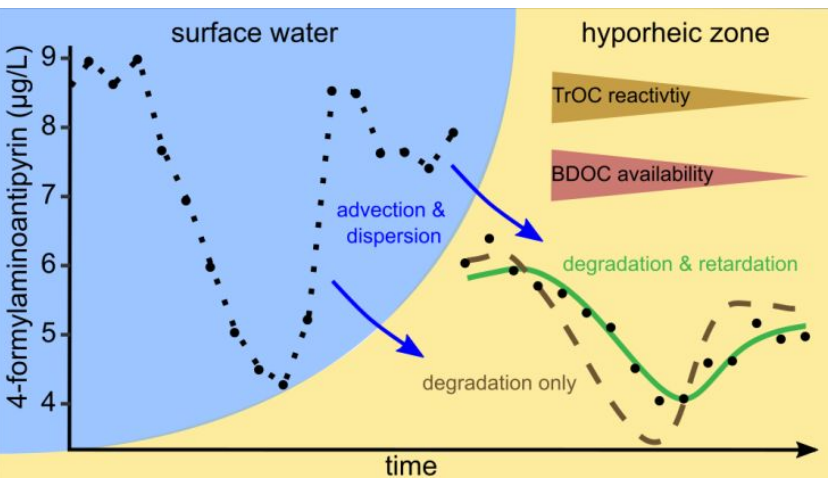




\section{Introduction}

37 Many trace organic compounds such as pharmaceuticals are only partially retained in wastewater 38 treatment plants (WWTPs) $)^{1,2}$ and thus are ubiquitous in urban surface waters. ${ }^{3,4}$ In rivers, TrOCs are of

39 eco-toxicological concern ${ }^{5-7}$ and the high persistence of some TrOCs in aquatic environments poses issues

40 for drinking water production. ${ }^{8}$ The hyporheic zone (HZ), the portion of the streambed in which surface

41 waters and groundwater mix, ${ }^{9}$ is generally regarded as an effective bioreactor, characterized by steep

42 redox gradients, diverse microbial communities and relatively high microbial turnover rates. ${ }^{10,11}$ Both

43 laboratory ${ }^{12,13}$ and field studies ${ }^{14,15}$ demonstrated that the HZ is able to efficiently remove many TrOCs,

44 even along relatively short flow paths $(<20 \mathrm{~cm})$. Therefore, the $\mathrm{HZ}$ may not only act as a filter protecting

45 groundwater form surface water contamination ${ }^{16}$ but also contributes to whole-stream, i.e. reach-scale

46 attenuation of TrOCs. ${ }^{17}$

47 The adequate assessment of the in-situ efficiency of the HZ in removing TrOCs requires a sound 48 understanding of both the in-situ reactivity and the exposure time of TrOCs to favorable attenuation 49 conditions. Hyporheic residence times are predominately controlled by transport characteristics such as 50 porewater velocity and dispersion. However, residence times of TrOCs along hyporheic flow paths may 51 also be influenced by sorption and desorption processes, i.e. retardation. ${ }^{18-20}$ Retardation can extend 52 residence times of TrOCs in the $\mathrm{HZ}$ and, if not considered in reactive transport modeling, may lead to an 53 overestimation of the in-situ reactivity of TrOCs in the HZ. Although retardation of some TrOCs in 54 saturated sediments has been demonstrated in laboratory studies ${ }^{20,21}$ little is known about its driving 55 factors and its overall importance for transport of TrOCs in hyporheic sediments.

56 Reactivity of TrOCs in the HZ increases with temperature ${ }^{12}$ and, for many TrOCs, is higher under oxic 57 conditions. ${ }^{12,14}$ However, since microbially mediated degradation and transformation mechanisms are 58 considered to be a main driver of TrOC removal in saturated sediments, it is likely that TrOC reactivity in 59 the $\mathrm{HZ}$ is also linked to microbial activity and growth and therefore to turnover of biodegradable dissolved 60 organic matter (BDOC). ${ }^{22}$ It has been shown that microbial activity in the HZ is typically highest in the 
61 shallow HZ (within the so called benthic bio-layer), where BDOC availability is highest and redox 62 conditions are rather oxic. ${ }^{10,23,24}$ It is therefore reasonable to assume that removal rates of TrOCs may vary 63 substantially along hyporheic flow paths, even if redox conditions are relatively similar. In previous 64 investigations on the fate of TrOCs in the HZ, neither retardation nor the effect of benthic bio-layers and 65 depth-dependent transport characteristics on the fate of TrOCs has been considered. ${ }^{14,15,25}$ In addition, 66 previous studies have mainly investigated the fate of parent TrOCs in the HZ, ${ }^{14,15,25}$ while information on 67 the fate of transformation products (TPs) such as guanylurea, the main TP of the antidiabetic drug 68 metformin, valsartan acid, the main TP of compounds of the sartan group, or gabapentin-lactam a main TP 69 of the anticonvulsant gabapentin in the $\mathrm{HZ}$ is widely lacking.

70 The objectives of the present study were to use concentration time series of TrOCs and conservative 71 tracers sampled along a $40 \mathrm{~cm}$ long hyporheic flow path to calculate depth-dependent in-situ retardation 72 coefficients and first-order removal rate constants of $28 \mathrm{TrOCs}$, including 7 transformation products, in 73 the HZ of an urban lowland river in Berlin, Germany. We hypothesize that hyporheic reactivities of 74 TrOCs are highest in the shallow HZ, where redox conditions are rather oxic and microbial activity is 75 highest. We further anticipate that many TrOCs are retarded along hyporheic flow paths, which notably 76 influences their residence times in the $\mathrm{HZ}$ and thus the estimation of hyporheic removal rates. 


\section{Methods}

78

79

80

\subsection{Site description and experimental overview}

River Erpe, an urban lowland river located east of Berlin, Germany, receives $60 \%$ to $80 \%$ of its discharge from the municipal WWTP Münchehofe. The present study was conducted at Heidemühle (Lat: 52.478647, Long: 13.635146), a section of River Erpe that has been subject to previous investigations on the fate of TrOCs in the HZ due to its sandy streambed sediments. ${ }^{14,15,26}$ Sediment characteristics at the sampling site were determined from one $40 \mathrm{~cm}$ long sediment core which was taken using a hand auger (inner diameter $9 \mathrm{~cm}$ ) in close proximity of the sampling site $(<10 \mathrm{~cm})$ and cut into $8 \mathrm{~cm}$ long sections, which were transferred into 5 KSAT rings (Meter, Germany) on site. Saturated hydraulic conductivity at $25^{\circ} \mathrm{C}$ was measured using a KSAT device (Meter, Germany) and ranged between $1.6 \times 10^{-5} \mathrm{~m} \mathrm{~s}^{-1}$ and 1.7 $\mathrm{x} 10^{-4} \mathrm{~m} \mathrm{~s}^{-1}$. Porosity, determined from oven dried $\left(105^{\circ} \mathrm{C}, 48 \mathrm{~h}\right)$ samples, decreased from 0.5 in the upper $8 \mathrm{~cm}$ of the $\mathrm{HZ}$ to 0.4 in the last 2 sub-cores (i.e. $24-40 \mathrm{~cm}$ depth).

The experimental setup consisted of three self-constructed mini-point samplers ${ }^{26}$ (compare section 2.2) that were installed in the $\mathrm{HZ}$ in 10, 30 and $40 \mathrm{~cm}$ depth (Figure 1). An additional mini-point sampler was installed in the $\mathrm{HZ}$ in $20 \mathrm{~cm}$ depth. However, due to clogging, the sampler in $20 \mathrm{~cm}$ depth provided only a limited number of samples and was thus excluded from further analysis. To gain additional information on the hydrological conditions at the study site and to cross-check porewater velocities determined by conservative transport modeling (section 2.5), porewater velocities were additionally calculated from temperature time series in the HZ. To this end, a Multi-Level Temperature Stick ${ }^{27}$ (MLTS, UIT, Dresden) was installed adjacent to the minipoint samplers $(\approx 10 \mathrm{~cm})$. Temperature time series were collected over the course of two weeks (14.06.-28.06.2016) in 5, 10, 15, 20, 30 and $50 \mathrm{~cm}$ depth in the HZ. Subsequently, vertical seepage fluxes and thermal dispersion coefficients were evaluated via the McCallum method ${ }^{28}$ incorporated in the VFLUX 2.0 program..$^{29}$ The McCallum method simultaneously uses phase shifts $(\Delta \varphi)$ and amplitude damping ratios $\left(\mathrm{A}_{\mathrm{r}}\right)$ of two sinusoidal temperature time series to calculate both the thermal dispersivity and the Darcy velocity via an analytical solution of the one- 
102 dimensional heat transport equation. In VFLUX, dynamic harmonic regression, ${ }^{30}$ a form of harmonic 103 regression in which the spectral coefficients describing a periodic signal can be non-stationary, is used to 104 estimate phase and amplitude information from the measured time series. Vertical seepage fluxes and thermal dispersion coefficients were calculated from measured temperature time series in 5 and $10 \mathrm{~cm}, 10$ and $30 \mathrm{~cm}$ and 20 and $50 \mathrm{~cm}$ depth in the HZ, yielding parameter estimates at center-of-pair depths of 7.5 $\mathrm{cm}, 20 \mathrm{~cm}$ and $35 \mathrm{~cm}$, respectively, covering the three different model sections in the HZ (compare section 2.5). Further details on the method and its underlying assumptions can be found elsewhere ${ }^{14,26}$ and in the Supporting Information (SI, section SI-01).

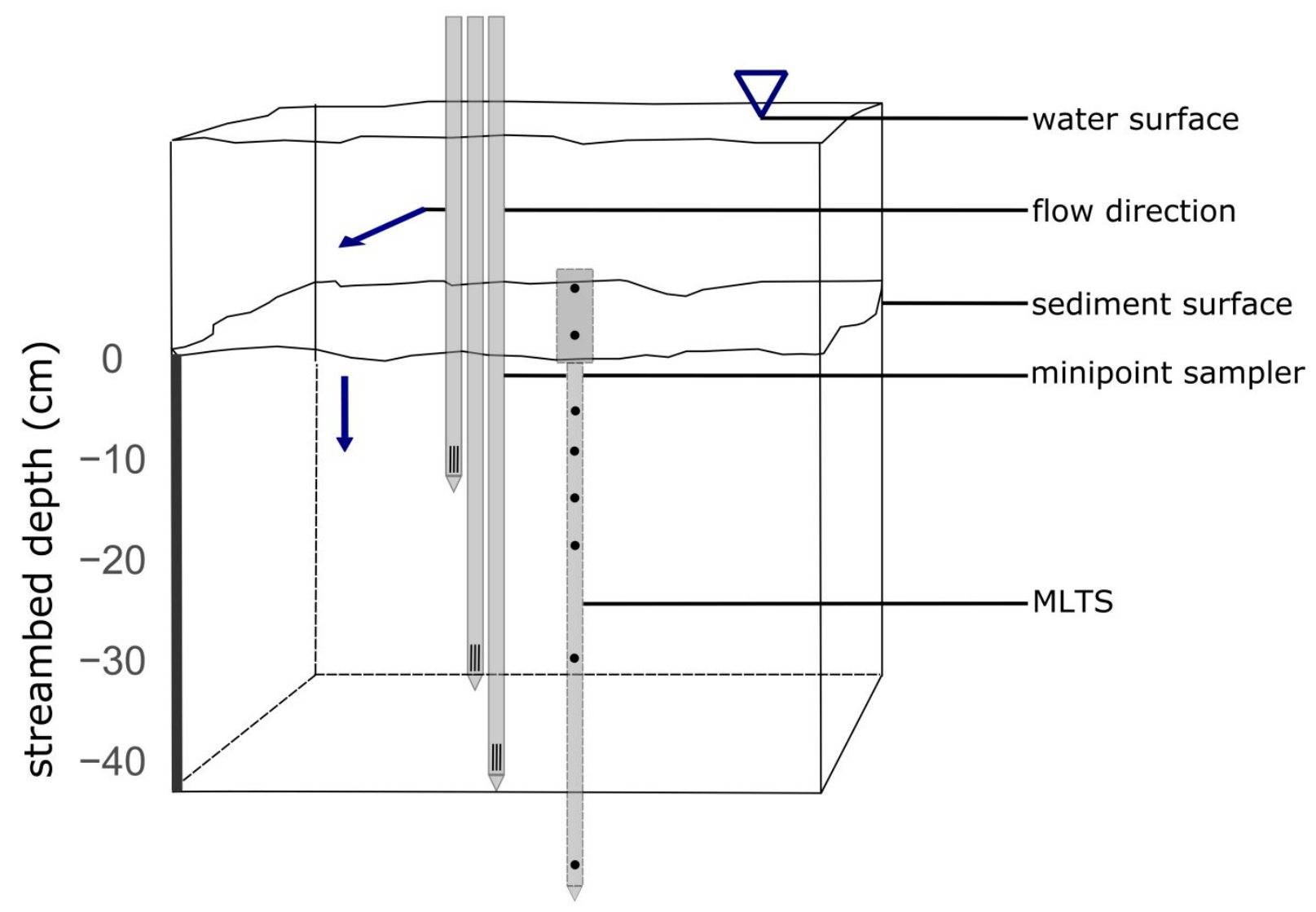

Figure 1 Experimental setup showing the three minipoint sampler installed in $10 \mathrm{~cm}, 30 \mathrm{~cm}$ and $40 \mathrm{~cm}$ depth in the hyporheic zone (HZ). The samplers were installed in a line $(<1 \mathrm{~cm}$ distance $)$ perpendicular to the water flow direction. A Multilevel Temperature Stick (MLTS) was installed in close proximity $(\approx 10 \mathrm{~cm})$ next to the minipoint sampler array. Blue arrows indicate surface water and predominant hyporheic flow directions. Minipoint samplers were sampled from an aluminum bridge spanning the river channel (not shown). 


\subsection{Water sampling}

118 Hyporheic porewater samples were collected hourly between $22: 30$ on June, $15^{\text {th }}$ and $15: 30$ on June $16^{\text {th }}$ 1192016 using self-constructed mini-point samplers. ${ }^{26}$ In brief, the mini-points consisted of HPLC tubes 120 (PEEK, ID 0.03 inch, Sigma Aldrich, USA) that were inserted into $1.5 \mathrm{~m}$ long stainless steel tubes (ID 0.7 $121 \mathrm{~mm})$. At the tip of the steel tubes, four $1-\mathrm{cm}$ long laser cut slits $(<0.1 \mathrm{~mm})$ allowed water flow but acted 122 as a filter screen for most sediment particles. The HPLC tubes were connected to a syringe pump (NE1231600 New Era Pump Systems, Inc, Farmingdale, USA) via Swagelok fittings (Swagelok, USA) to allow 124 slow, constant pumping of hyporheic porewater. Thirteen $\mathrm{ml}$ of hyporheic porewater were sampled 125 applying a constant sampling rate of $1 \mathrm{ml} \mathrm{min}^{-1}$. In previous investigations conducted at the same site 126 pumping rates of $1 \mathrm{ml} \mathrm{min} \mathrm{m}^{-1}$ have been found to be sufficiently low to maintain the integrity of the 127 hyporheic flow field. ${ }^{26}$ Electrical conductivity (EC) was measured in each sample and in the surface water 128 using handheld EC meters (GMH 3431, Greisinger, Germany). Every four hours, pH was measured in the 129 hyporheic porewater samples and in the surface water using a handheld $\mathrm{pH}$ meter (SenTix 41, WTW, 130 Germany), calibrated prior to sampling. Samples in the HZ were related to surface water samples, 131 obtained from an automatic water sampler (model 3700, Teflon suction line, Teledyne ISCO, Lincoln, 132 NE.) located $150 \mathrm{~m}$ upstream of the sampling site following procedures described elsewhere. ${ }^{31}$ Samples 133 for TrOC and dissolved organic carbon (DOC) analysis were filtered through regenerated cellulose 134 syringe filters $(0.2 \mu \mathrm{m}$, Macherey-Nagel, Germany) and stored in amber glass bottles with Teflon lined 135 caps. Samples for TrOC analysis were immediately frozen on site. Samples for DOC analysis were stored 136 at $4^{\circ} \mathrm{C}$ in the dark and were measured within two weeks after sampling. Samples for $\mathrm{NO}_{3}{ }^{-} \mathrm{N}$ and major 137 cation analysis were filtered through cellulose acetate syringe filters ( $0.2 \mu \mathrm{m}$, Sartorius, Germany) and 138 stored in polyethylene bottles at $4{ }^{\circ} \mathrm{C}$ until analysis. Samples for total dissolved iron and dissolved 139 manganese analysis were additionally acidified to $\mathrm{pH} \approx 2.0$ using $\mathrm{HCl}$. A sampling period of $17 \mathrm{~h}$ was 140 considered sufficient as the aim of the present study was to investigate TrOC reactivity and the effect of 141 retardation on TrOC transport along a relatively constrained hyporheic flow path. From previous studies at 
142 the same field site it was known that (i) chemical conditions in River Erpe oscillate on a daily basis 143 (concentration troughs in the morning, peaks in the afternoon) but are relatively constant over the course 144 of weeks and (ii) that porewater velocities were in the order of several cm per hour. ${ }^{14,31}$ 


\subsection{Analytical procedures}

147 To enlarge the number of target compounds, samples were split and analyzed in parallel using high 148 performance liquid chromatography with tandem mass spectrometry (HPLC-MS/MS) at the Department 149 of Environmental Science and Analytical Chemistry (ACES) at Stockholm University and the Chair of 150 Water Quality Engineering at Technical University of Berlin (TUB) following standard protocols 151 established previously. ${ }^{26,32,33}$ In brief, separation of TrOCs was achieved via a XSelect HSS T3 HPLC 152 column $(2.5 \mu \mathrm{m}$ particle size, $2.1 * 50 \mathrm{~mm}$, Waters, USA $)$ at TUB and an Acquity UPLC HSS T3 column $153(1.8 \mu \mathrm{m}, 2.1 \mathrm{~mm} \times 100 \mathrm{~mm}$, Waters, USA) at ACES. Both protocols used linear gradients (ultra-pure 154 water versus 100\% methanol; HPLC grade, J.T. Baker, USA). A TSQ Vantage (Thermo Fisher Scientific, 155 USA) and a Quantiva triple-quadrupole mass spectrometer in ESI \pm modes were used for MS/MS analysis 156 at TUB and ACES, respectively. In both methods, TrOC were identified based on the characteristic ratio 157 of two ion fragments and quantified via isotope-substituted standards (Toronto Research Chemicals, 158 Canada) in combination with the most abundant fragment ion (Table SI-01). In both methods, a series of calibration standards was measured before and after each sampling sequence. To assess analytical errors, samples at TUB were measured in triplicate, while at ACES quality control standards were measured during each run. In total, 29 TrOCs, including 22 parent compounds (PCs) and 7 transformation products

162 (TPs), were analyzed in the present study. Ultra-pure water (Maxima UF device, ELGA LabWater, 163 Germany) and tap water were measured as method blank at TUB and ACES, respectively. Limits of detection (LODs) and quantification (LOQs) for each target compound and additional information on the analytical procedures and data evaluation are provided in the SI (section 2). Concentrations of major cations and total dissolved iron and manganese were measured using inductively coupled plasma optical emission spectrometry (ICP-OES, ICP iCAP 6000series, Thermo Fisher). Nitrate-N concentrations were measured via continuous-flow-analysis (SAN ++, Skalar) following DIN EN ISO 13395. 
$171250-550 \mathrm{~nm} 1.64 \mathrm{~nm}$ increments) were measured in triplicate at a Horiba Aqualog (Horiba Ltd, Japan) in 172 a $1 \mathrm{~cm}$ quartz cuvette. One blank (MiliQ water) was measured for every 9 measurements. Scan speed was $17312000 \mathrm{~nm} \mathrm{~min}^{-1}$ at a response time of $0.01 \mathrm{~s}$. The Humification Index (HIX), a measure of the degree of 174 humification of DOM, ${ }^{34}$ was calculated after EEMs were blank-subtracted and corrected for the inner 175 filter effect. DOC concentration was measured in triplicate at a varioTOC cube (elementar 176 Analysensysteme, Germany). Specific UV absorbance at $254 \mathrm{~nm}\left(\mathrm{SUVA}_{254}\right)$ was calculated by 177 normalizing the decadal absorbance measured at $254 \mathrm{~nm}$ to DOC concentration $(\mathrm{mg} / \mathrm{L}){ }^{35}$

\subsection{Calculation of relative removal percentages}

179 To assess overall TrOC removal along the investigated hyporheic flow path and to cross-validate 180 calculated removal rate constants (section 2.5), relative TrOC removals were calculated between the 181 surface water and hyporheic water in $40 \mathrm{~cm}$ depth and between other pairs of concentration time series, 182 i.e., between the surface water and hyporheic water in $10 \mathrm{~cm}$ depth, between hyporheic water in 10 and in $18330 \mathrm{~cm}$ depth and between hyporheic water in 30 and in $40 \mathrm{~cm}$ depth. Because measured concentrations 184 varied with time, relative removal of a given TrOC $(\mathrm{x})$ between two sampling depths $\left(\operatorname{Rel}_{\mathrm{x}}\right)$ was calculated 185 using cumulative concentrations of a TrOC normalized to cumulative concentrations of a stable reference 186 compound: ${ }^{36,37}$

$$
\operatorname{Rel}_{x}^{\text {in }- \text { out }}=\left(1-\frac{\sum_{i}^{n} c_{x, \text { out }, i} \sum_{i}^{n} c_{r e f, i n, i}}{\sum_{i}^{n} c_{x, i n, i} \sum_{i}^{n} c_{r e f, o u t, i}}\right) x 100 \%
$$

188 whereby $c_{x, \text { in }}$ and $c_{x, \text { out }}\left(c_{r e f, \text { in }}\right.$ and $\left.c_{r e f, o u t}\right)$ are the concentrations of the upper and lower concentration time 189 series of a TrOC (a stable reference compound), respectively, and $\mathrm{n}$ is the number of data points in each 190 time series. In the present study we used $O$-desmethylvenlafaxine (MLX) as a stable reference compound 191 as it showed low retardation along the hyporheic flow path and was found to be rather stable in the HZ 192 (compare section 3.3). The approach was cross-validated using the diurnal varying EC signal measured in 
193 the surface water and in hyporheic porewater samples as another conservative reference (SI section 4). 194 Removal of a TrOC was considered significant if the $95 \%$ confidence interval of the relative removal, 195 computed using the respective analytical uncertainties of each TrOC (Table SI-02), did not include zero.

196 The applicability of equation 1 requires either relatively constant flow conditions or a positive correlation 197 between the reference compound and the target TrOC concentrations. Both requirements were likely met 198 in the present study as the study site was characterized by strong downwelling conditions (compare 199 section 3.1) and concentrations of TrOCs (with the exception of acesulfame, metoprolol acid and 200 metformin) were well correlated to $O$-desmethylvenlafaxine concentrations (Pearson Product Moment 201 Correlation coefficients $>0.7, \mathrm{p}$-value $<0.05$ ). Equation 1 is based on the assumption that the transport 202 time scales of both, the target TrOC and the reference compound, are similar. Thus Rel $_{\mathrm{x}}$ calculated for 203 strongly retarding TrOCs (compare section 3.4) should be treated with caution. 


\subsection{Reactive transport modeling}

Measured concentration time series in the HZ were evaluated using the one-dimensional (1D) advectiondispersion transport equation including first-order degradation and retardation (1D-ADE). Assuming steady and uniform flow in a homogeneous medium, and time invariant dispersion, retardation and firstorder decay the $1 \mathrm{D}-\mathrm{ADE}$ equation can be written as:

$$
R \frac{\partial c}{\partial t}=D_{h} \frac{\partial^{2} c}{\partial x^{2}}-v \frac{\partial c}{\partial x}-\lambda c
$$

where $c$ denotes the concentration of a (reactive) compound, $D_{h}$ the effective hydrodynamic dispersion coefficient $\left(\mathrm{m}^{2} \mathrm{~h}^{-1}\right), v$ the vertical porewater velocity $\left(\mathrm{m} \mathrm{h}^{-1}\right), \lambda$ a first-order removal rate constant $\left(\mathrm{h}^{-1}\right)$ and

$212 R$ the retardation coefficient (-). Equation 2 was implemented in the programming language Python and 213 solved numerically using a finite-difference scheme. The HZ was vertically divided into three sections 214 delimited by each pair of concentration time series: Section 1 between the surface water and $10 \mathrm{~cm}$ depth, 215 section 2 between 10 and $30 \mathrm{~cm}$ depth and section 3 between 30 and $40 \mathrm{~cm}$ depth. For each section in the $216 \mathrm{HZ}$, equation 2 was solved separately, yielding independent parameter estimates for each section. The 217 upper concentration time series served as an upper boundary condition in equation 2 . The lower boundary 218 condition (in 100, 110 and $120 \mathrm{~cm}$ depth for sections 1, 2 and 3, respectively) was set to zero. The lower concentration time series in each section was used for parameter estimation. Parameter estimation was achieved using the DREAM algorithm, ${ }^{38,39}$ a Bayesian parameter optimization method which employs evolutionary Monte Carlo Markov chains to estimate posterior probability density distributions (posteriors) of model parameters. In a first step, posteriors of conservative transport characteristics (i.e. $v$ and $D_{h}$ ) were estimated from EC time series by setting $\lambda$ to zero and R to unity. In a second step, measured concentrations of TrOCs, $\mathrm{DOC}$ and $\mathrm{NO}_{3}^{-}-\mathrm{N}$ were used to derive first-order removal rate constants and, for TrOCs, retardation coefficients using the previously derived posteriors for $v$ and $D_{h}$

226 as priors. This approach was justified as the relative contribution of molecular diffusion to $D_{h}$, which at 227 sediment-water interface is commonly described as the sum of molecular, hydrodynamic and turbulent 
228 diffusivities, ${ }^{40,41}$ can be considered negligible, because porewater velocities measured in the present study 229 were larger than $10^{-6} \mathrm{~m} \mathrm{~s}^{-1}$ (compare section 3.1) and molecular diffusion coefficients $\left(D_{m o l}\right)$ for the 230 investigated TrOCs are generally smaller than $10^{-9} \mathrm{~m}^{2} \mathrm{~s}^{-1}$ (Table SI-03, see SI section 3.3 for details on 231 calculation of $\left.D_{m o l}\right)$.

232 Retardation coefficients can only be estimated from measured concentration time series that show a 233 distinct, traceable temporal pattern, i.e., a trough or peak. For TrOCs, parameter optimization via DREAM 234 was therefore conducted using two models, one including $(R \geq 1)$ and one excluding the effect of 235 retardation $(R=1)$. If retardation coefficients could not be estimated, i.e., if posteriors of $\mathrm{R}$ were indifferent 236 from their priors, $\lambda$ was estimated from the model in which $R$ was set to unity. The conceptual model of 237 equation 2 assumes that i) water flows vertically from the surface into the $\mathrm{HZ}$ and that ii) mixing with 238 groundwater can be neglected. These assumptions were justified as i) the study site was characterized by 239 strong downwelling conditions (compare section 3.1) and a previous investigation on hyporheic flow 240 fields at the same site found that horizontal flow components were of minor importance ${ }^{14}$ and ii) relative 241 removal of $O$-desmethylvenlafaxine, a stable reference compound (compare section 2.4), was calculated to 242 be -3 to $4 \%$ (Table 2) indicating that groundwater input along the investigated flow path was negligible. 243 Details on the numerical scheme used to solve equation 2 and the parameter estimation procedure 244 including the prior distributions of model parameters and other DREAM settings are provided in the SI.

\section{3. Results \& Discussion}

\section{$246 \quad 3.1$ Transport characteristics in the hyporheic zone}

247 Median porewater velocities, estimated from temperature depth profiles using VFLUX, ranged between

2480.06 and $0.11 \mathrm{~m} \mathrm{~h}^{-1}$ (Table 1). These strong downwelling conditions (positive flux = downward flow) are

249 in line with values reported previously for the same study site. ${ }^{14}$ As a result of low WWTP discharge 250 during nighttime, EC time series in the surface water of River Erpe follow a saw-toothed pattern with 251 distinct EC troughs in early morning hours. ${ }^{14}$ The EC trough, measured in the surface water between 02:00 
252 and 10:00 on June $16^{\text {th }}$ propagated into the $\mathrm{HZ}$ and served as a natural tracer from which conservative 253 transport parameters were modeled using equation 2 (Figure 2). Porewater velocities derived from EC 254 time series using the 1D-ADE model ranged from $0.07 \mathrm{~m} \mathrm{~h}^{-1}$ to $0.17 \mathrm{~m} \mathrm{~h}^{-1}$ and are thus somewhat higher 255 than porewater velocities calculated from temperature time series using VFLUX, particularly in the upper 256 two sections of the HZ (Table 1). Differences in porewater velocities might be the result of erroneous 257 VFLUX calculations (e.g., due to violations of VFLUX model assumptions) and sediment heterogeneity.

258 Values for the effective hydrodynamic dispersion coefficient $\left(D_{h}\right)$ ranged between $10 \times 10^{-4}$ and $48 \times 10^{-4}$ $259 \mathrm{~m}^{2} \mathrm{~h}^{-1}$ and are within the same order of magnitude as values of the effective thermal dispersion coefficient 260 calculated by VFLUX $\left(D_{t}\right.$, Table 1$)$.

Table 1 Mean values ( \pm 1 standard deviation) of porewater velocities $(v)$ and dispersion coefficients (hydrodynamic dispersion coefficient $D_{h}$, thermal dispersion coefficient $D_{t}$ ) derived from i) electrical conductivity (EC) time series using eqn. 2 (1D-ADE) and ii) from temperature time series using VFLUX 2.0 for all three sections in the hyporheic zone. In addition, removal rates of $\mathrm{NO}_{3}{ }^{-}-\mathrm{N}\left(\mathrm{k}_{\text {nit-N }}\right)$ and DOC $\left(\mathrm{k}_{\text {DOC }}\right)$ are shown.

\begin{tabular}{ccccccc}
\hline depth & \multicolumn{2}{c}{ 1D-ADE } & \multicolumn{2}{c}{ VFLUX 2.0 } & $\mathrm{NO}_{3}-\mathrm{N}$ & DOC \\
& $v$ & $D_{h}$ & $v$ & $D_{t}$ & $\mathrm{k}_{\text {nit-N }}$ & $\mathrm{k}_{\text {DOC }}$ \\
$\mathrm{cm}$ & $\mathrm{m} \mathrm{h}^{-1}$ & $\mathrm{~m}^{2} \mathrm{~h}^{-1} \times 10^{-4}$ & $\mathrm{~m} \mathrm{~h}^{-1}$ & $\mathrm{~m}^{2} \mathrm{~h}^{-1} \times 10^{-4}$ & $\mathrm{~h}^{-1}$ & $\mathrm{~h}^{-1}$ \\
$0-10$ & $0.14 \pm 0.01$ & $48 \pm 6$ & $0.11 \pm 0.02$ & $73 \pm 05$ & $0.60 \pm 0.03$ & $0.30 \pm 0.01$ \\
$10-30$ & $0.17 \pm 0.01$ & $10 \pm 3$ & $0.07 \pm 0.01$ & $34 \pm 01$ & $0.10 \pm 0.01$ & $0.12 \pm 0.01$ \\
$30-40$ & $0.07 \pm 0.01$ & $46 \pm 12$ & $0.06 \pm 0.01$ & $36 \pm 01$ & $1.25 \pm 0.03$ & $0.05 \pm 0.01$ \\
\hline
\end{tabular}




\subsection{Redox zonation and DOC dynamics in the hyporheic zone}

268 DOC concentrations gradually decreased along the investigated hyporheic flow path, while $\mathrm{SUVA}_{254}$ and 269 HIX, measures of the aromaticity and the degree of humification of DOC, respectively increased (Figure 270 SI-04). A general decrease of DOC concentrations and an increase of $\mathrm{SUVA}_{254}$ along hyporheic flow 271 paths has been reported previously ${ }^{42}$ and was attributed to preferred degradation of non-aromatic, 272 biodegradable DOC fractions in the HZ. The largest removal rate of DOC as well as the largest change in 273 HIX occurred between 0 and $10 \mathrm{~cm}$ depth (Table 1, Figure SI-04), suggesting that the largest change in 274 DOC quantity and quality along the investigated hyporheic flow path occurred in the upper $10 \mathrm{~cm}$ of the HZ. This finding is in agreement with previous investigations in the HZ, suggesting that the highest carbon turnover rates in the $\mathrm{HZ}$ are typically found within the first $\mathrm{cm}$ of the $\mathrm{HZ}$ in the so called active benthic bio-layer. ${ }^{10}$ A more detailed discussion of DOC dynamics in the $\mathrm{HZ}$ including information on other EEM indices is provided in the SI (SI section 6).

During the sampling period, nitrate concentrations in the surface water were high (median concentrations $7.0 \mathrm{mg} / \mathrm{L} \mathrm{NO}_{3}^{-}-\mathrm{N}$, Table SI-04). In the $\mathrm{HZ}$, nitrate removal rates were high between 0 and $10 \mathrm{~cm}$ depth, low between 10 and $30 \mathrm{~cm}$ depth and highest between 30 and $40 \mathrm{~cm}$ depth (Figure SI-03, Table 1). Concentrations of total dissolved iron and dissolved manganese in the $\mathrm{HZ}$ were relatively low $(<0.05$ $\mathrm{mg} / \mathrm{L}$, Table SI-04), indicating the redox conditions in the stream sediment were not yet within iron- and manganese-reducing ranges. Removal of nitrate- $\mathrm{N}$ in the $\mathrm{HZ}$ can be caused by microbial uptake (i.e., assimilation) and denitrification occurring in both anoxic sections of the HZ and in anoxic microzones. ${ }^{42-}$ ${ }^{44}$ Because DOC removal rates were highest in the shallow HZ, it is reasonable to assume that in addition to potential denitrification in anoxic microzones, ${ }^{23}$ nitrate-N removal in the upper $10 \mathrm{~cm}$ in the $\mathrm{HZ}$ was primarily caused by biotic assimilation. The higher nitrate-N removal rate in the deeper HZ (i.e., between 30 and $40 \mathrm{~cm}$ depth), however, is presumably attributable to denitrification. It is therefore likely that redox conditions in the bulk porewater were rather oxic in the first $30 \mathrm{~cm}$ of the $\mathrm{HZ}$ and became suboxic (i.e. 
292 microbial turnover rates and the abundance and quality of electron acceptors and donors, physical 293 parameters such as temperature and transport characteristics that control residence time distributions in the 294 HZ. Compared to earlier investigations on redox zonation in the $\mathrm{HZ}$ at the same study site, ${ }^{14}$ redox 295 zonation in the present study was shifted downwards (i.e. deeper onset of denitrification and 296 iron/manganese reduction). In line with previous studies, ${ }^{23}$ we attribute this finding to larger porewater 297 velocities measured in the present study.

298 


\subsection{Reactivity of trace organic compounds in the $\mathrm{HZ}$}

300 Out of the 29 investigated TrOCs, relative removals (\%) and first-order removal rates could be calculated

301 from measured concentration time series of 28 compounds (Table 2). For epoxy-carbamazepine (EBZ), 302 concentrations were either below LOQ or just slightly above LOQ and thus EBZ was not considered in 303 further analysis (Table SI-04). Modeled and measured concentration time series for valsartan acid (VSA), 304 metformin (MEF) and its TP guanylurea (GUA) and EC are depicted in Figure 2. Measured and modeled 305 concentration time series of the remaining TrOCs are shown in Figures SI 05-32. Twenty-two compounds were significantly removed between the surface water and $40 \mathrm{~cm}$ depth with half-lives within the first 10 $\mathrm{cm}$ of the $\mathrm{HZ}$ ranging between $0.1 \pm 0.01 \mathrm{~h}$ for iopromide and $3.5 \pm 0.3 \mathrm{~h}$ for tramadol (Table 2).

The highest removal rate constants were calculated for the iodinated X-ray contrast agents iomeprol (IOM) and iopromide (IOP). Complete de-iodination of both compounds in saturated sediments has only been observed under anoxic redox conditions ${ }^{45}$ but both compounds are known to readily loose side chains

311 of the iodinated ring structure under aerobic conditions..$^{46,47}$ It is therefore likely that the high removal

312 rates calculated in the present study are due to transformation of both compounds and do not represent 313 complete mineralization. Removal of the artificial sweetener acesulfame (ACS), the lipid-lowering agent 314 bezafibrate (BZF), the anti-corrosive agents benzotriazole and methylbenzotriazole and the anticonvulsant 315 GAB along oxic to suboxic (i.e. denitrifying) flow paths in hyporheic sediments has previously been 316 described in laboratory column experiments ${ }^{12,48}$ and observed in the HZ. ${ }^{14}$ For ACS, reported half-lives 317 range from $1.2^{14}$ to $5^{12} \mathrm{~h}$ and for $\mathrm{BZF}$ and GAB were calculated to be $1.2 \mathrm{~h}$ and $0.96 \mathrm{~h}$ in a previous 318 investigation at the same site. ${ }^{14}$ Thus, half-lives for ACS, BZF and GAB calculated in the present study 319 match half-lives calculated previously for hyporheic sediments. Removal of gabapentin-lactam, a major $320 \mathrm{TP}$ of $\mathrm{GAB},{ }^{48}$ in saturated sediments has previously been reported during bank filtration, with half-lives 321 between 1.2 and $3.7 \mathrm{~h} .{ }^{49}$ These values match the ones calculated for the first $10 \mathrm{~cm}$ of the $\mathrm{HZ}(2.3 \pm 0.2 \mathrm{~h})$, 322 although no further removal of GPL was observed in deeper section of the HZ. 
323 Although the antidiabetic drug metformin and its main TP guanylurea ${ }^{50}$ have been detected ubiquitously in 324 surface waters, ${ }^{51,52}$ qualitative information on the fate of the two compounds in saturated sediments is 325 relatively scarce. Both were found to be rather stable in laboratory batch experiments; ${ }^{50,53}$ a finding that 326 cannot be confirmed in the present study where they show half-lives in the HZ of several hours. 327 Calculated half-lives for the beta-blockers MTP are in line with findings of a laboratory column study 328 reporting half-lives of several hours for oxic/suboxic conditions, ${ }^{12}$ but contrast results of investigations 329 conducted previously at the same study site, in which MTP was, on average, not significantly removed 330 along a $20 \mathrm{~cm}$ long hyporheic flow path. ${ }^{14}$ Metoprolol acid (MTA), a main TP of MTP, was formed in the 331 HZ, suggesting that removal of MTP in the HZ is at least in part due to transformation into MTA. 332 Quantitative information on the fate of the beta blocker sotalol (SOT) and the opioid analgesic tramadol 333 (TRA) in the HZ is limited. For SOT and TRA, a concentration decrease in the $\mathrm{HZ}^{25}$ and in sediments of a 334 flume study mimicking the $\mathrm{HZ},{ }^{13}$ respectively, has been reported, but no removal rates were calculated. 335 The antihypertensive drugs olmesartan (OLM), irbesartan (IRB), candesartan (CAN) and valsartan (VAL) were significantly removed along the investigated flow path. Simultaneously concentrations of their common TP valsartan acid ${ }^{54,55}$ (VSA) increased. At least part of the removal of OLM, CAN, VAL and 338 IRB can therefore be attributed to transformation to VSA. While VAL removal in hyporheic sediments 339 has been described, ${ }^{17}$ OLM and CAN were found to be rather stable in both, hyporheic sediments and 340 during river bank filtration. ${ }^{17,49}$ Although removal of VSA has been described in bank filtration systems, ${ }^{49}$ 341 concentrations of its PCs were likely too high in the HZ and thus net formation rates were higher than 342 potential VSA removal rates.

343 Carbamazepine (CBZ) and one of its TPs dihydroxy-carbamazepine (DBZ), diclofenac (DCF), diatrizoic 344 acid (diatrizoate, DTA) and venlafaxine (VLX) and its TP $O$-desmethylvenlafaxine (MLX) were not 345 significantly removed and were thus considered to be rather stable along the investigated flow path (Table 346 2). CBZ is well known for its stability in saturated sediments ${ }^{56}$ and hitherto, removal has only been 347 observed under iron-reducing conditions after long (several days) residence times. ${ }^{57}$ Since concentrations 
348 of DBZ remained relatively constant along the investigated flow path it is reasonable to assume that 349 transformation of CBZ to DBZ along short $(<40 \mathrm{~cm})$ and rather oxic flow paths in the $\mathrm{HZ}$ is limited. 350 Laboratory and field studies have demonstrated that VLX, ${ }^{58} \mathrm{DCF}^{12,14}$ and $\mathrm{DTA}^{59}$ can be removed in 351 saturated sediments. It is therefore likely that in the present study exposure times to favorable 352 biogeochemical conditions in the HZ times were likely too short to facilitate significant removal of these 353 compounds.

354 The anticonvulsant primidone (PRI) and the antibiotic sulfamethoxazole (SMX) showed negative removal 355 indicating a concentration increase in the HZ. To the best of our knowledge, formation of PRI in the HZ 356 has not been reported and we thus attribute the small concentration increase $(18 \pm 7 \%)$ to desorption 357 processes. For SMX however, back-transformation of photo-transformation products into SMX has been 358 observed in water/sediment systems. ${ }^{60}$ It is therefore perceivable that back-transformation was responsible 359 for the observed concentration increase of SMX. The TrOC 4-formylaminoantipyrin (FAA), a human 360 metabolite of metamizole ${ }^{61}$ (a phenazone-type analgesics not investigated in the present study), was found 361 to be removed between 0 and $30 \mathrm{~cm}$ depth but was formed between 30 and $40 \mathrm{~cm}$ depth. Removal of FAA 362 in oxic sections of saturated sediments has been described, ${ }^{12,62}$ although a previous investigation at the 363 same site found inconsistent behavior (removal in some profiles, formation in others) of the compound. ${ }^{14}$ 364 It remains unclear whether the formation of FAA during suboxic (i.e. denitrifying) redox conditions is due 365 to back-transformation or due to increased transformation of its $\mathrm{PC}(\mathrm{s})$.

366 For some compounds (e.g. OLM), modeled concentration time series could be fitted well over the entire 367 time series. For other compounds such as MTP, VSA or GUA (Figure 1, Figure SI-24), modeled 368 concentrations matched measured concentration time series well in some parts of the time series but 369 deviated in others. Such discrepancies indicate that model assumptions such as time invariant porewater 370 velocities or removal rate constants were not met throughout the sampling event. Time varying removal 371 rate constants could be the consequence of temperature dependent biotransformation rates or varying 372 substrate and TrOC concentrations in the surface water. 

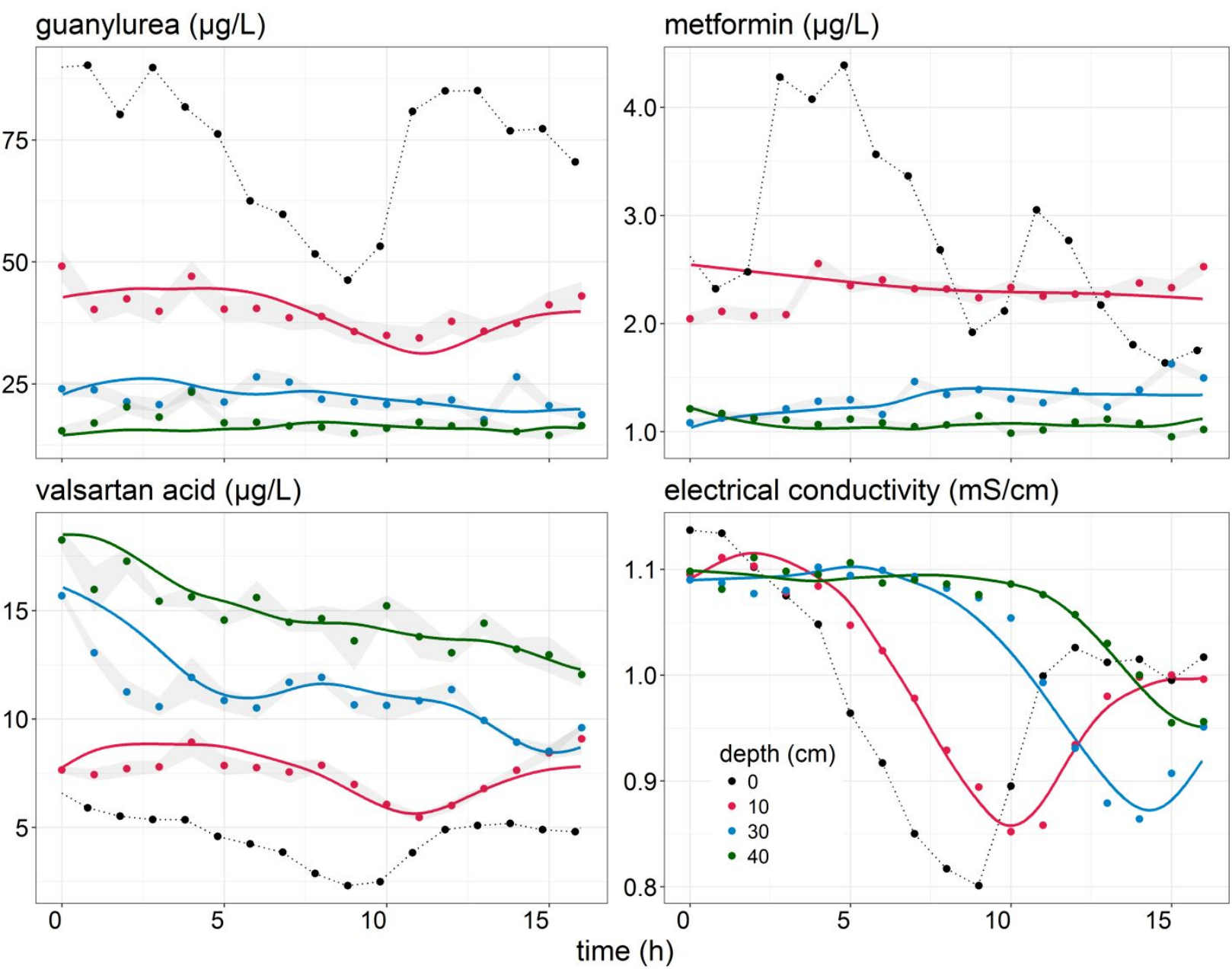

time $(\mathrm{h})$

Figure 2 Measured (dots) and modeled (solid lines) concentration time series in $10 \mathrm{~cm}, 30 \mathrm{~cm}$ and $40 \mathrm{~cm}$ depth in the hyporheic zone (HZ) and measured concentration time series in the surface water $(0 \mathrm{~cm})$ of guanylurea (GUA), metformin (MEF), valsartan acid (VSA) and electrical conductivity (EC). For concentration time series measured in the HZ, analytical uncertainty (one standard deviation) is shown in grey. Note that for modeling purposes, concentration time series in the surface water were linearly interpolated (black dashed line) and that for EC no measurement uncertainties were available. 
Table 2 Relative removal in the upper $40 \mathrm{~cm}$ of the hyporheic zone $\left(\operatorname{Rel}_{\mathrm{x}}{ }^{0-40}, \%\right)$, half-lives $\left(\mathrm{t}_{1 / 2}, \mathrm{~h}\right)$ and retardation coefficients $(\mathrm{R}$, dimensionless) of all trace organic compounds investigated in the present study except epoxy-carbamazepine calculated between 0 and 10, 10 and 30 and 30 and $40 \mathrm{~cm}$ depth in the hyporheic zone. Note that retardation coefficients could only be estimated from input time series that showed a distinct temporal pattern, i.e. a trough or peak. Half-lives exceeding the sampling period (i.e.,

$38417 \mathrm{~h}$ ) were set to infinity.

\begin{tabular}{|c|c|c|c|c|c|c|c|}
\hline \multirow[t]{2}{*}{$\mathrm{TrOC}$} & \multirow{2}{*}{$\begin{array}{c}\mathrm{Rel}_{\mathrm{X}}{ }^{0-40} \\
(\%) \\
0-40\end{array}$} & \multicolumn{3}{|c|}{$\mathrm{t}_{1 / 2}(\mathrm{~h})$} & \multicolumn{3}{|c|}{$\mathrm{R}(-)$} \\
\hline & & $0-10$ & $10-30$ & $30-40$ & $0-10$ & $10-30$ & $30-40$ \\
\hline acesulfame (ACS) & $78 \pm 1$ & $0.5 \pm 0.0$ & $2.9 \pm 0.2$ & $0.9 \pm 0.0$ & $1.2 \pm 0.1$ & 1.0 & n.e. \\
\hline benzotriazole (BTA) & $63 \pm 2$ & $0.9 \pm 0.0$ & $2.6 \pm 0.1$ & $12.6 \pm 2.6^{*}$ & $4.0 \pm 0.5$ & n.e. & n.e. \\
\hline bezafibrate (BZF) & $69 \pm 2$ & $0.8 \pm 0.0$ & $3.7 \pm 0.1$ & $1.9 \pm 0.2$ & $2.6 \pm 0.3$ & $2.8 \pm 0.0$ & n.e. \\
\hline candesartan (CAN) & $27 \pm 4$ & $1.1 \pm 0.1$ & $12.9 \pm 3.8^{\mathrm{f}, *}$ & inf & $1.7 \pm 0.2$ & $1.3 \pm 0.1$ & n.e. \\
\hline carbamazepine (CBZ) & $9 \pm 5^{*}$ & $9.8 \pm 1.6$ & inf & inf & $3.6 \pm 0.3$ & n.e. & n.e. \\
\hline dihydroxy-carbamazepine (DBZ) & $-1 \pm 6^{*}$ & $3.2 \pm 0.4^{*}$ & $11.4 \pm 5.3$ & $15.8 \pm 8.9^{f}$ & $2.2 \pm 0.3$ & n.e. & n.e. \\
\hline diclofenac (DCF) & $-11 \pm 6^{*}$ & inf & inf & inf & $4.3 \pm 0.3$ & n.e. & n.e. \\
\hline diatrizoic acid (DTA) & $0 \pm 9 *$ & $6.3 \pm 1.4^{*}$ & inf & inf & $1.1 \pm 0.1$ & $2.0 \pm 2.5$ & n.e. \\
\hline 4-formylaminoantipyrine (FAA) & $10 \pm 4$ & $1.2 \pm 0.1$ & inf & $9.4 \pm 0.9^{f}$ & $2.4 \pm 0.2$ & $1.5 \pm 0.1$ & n.e. \\
\hline gabapentin (GAB) & $79 \pm 1$ & $0.4 \pm 0.0$ & $1.5 \pm 0.0$ & $2.1 \pm 0.1$ & $1.4 \pm 0.0$ & $1.4 \pm 0.1$ & $3.7 \pm 0.6$ \\
\hline gabapentin-lactam (GPL) & $12 \pm 5$ & $2.3 \pm 0.2$ & $8.9 \pm 1.4^{\mathrm{f}, *}$ & inf & $1.3 \pm 0.2$ & n.e. & n.e. \\
\hline guanylurea (GUA) & $78 \pm 1$ & $0.6 \pm 0.0$ & $1.4 \pm 0.0$ & $2.8 \pm 0.3$ & $2.6 \pm 0.2$ & n.e. & n.e. \\
\hline iomeprol (IOM) & $98 \pm 0$ & $0.1 \pm 0.0$ & $0.7 \pm 0.0$ & $0.7 \pm 0.1$ & $1.9 \pm 0.4$ & $1.1 \pm 0.1$ & n.e. \\
\hline iopromid (IOP) & $98 \pm 0$ & $0.1 \pm 0.0$ & $0.8 \pm 0.1$ & $0.6 \pm 0.3$ & n.e. & n.e. & n.e. \\
\hline irbesartan (IRB) & $37 \pm 3$ & $1.0 \pm 0.0$ & $7.1 \pm 1.3^{f}$ & $3.9 \pm 0.6$ & $3.5 \pm 0.1$ & n.e. & n.e. \\
\hline methylbenzotriazole (MBT) & $36 \pm 3$ & $1.7 \pm 0.0$ & $4.1 \pm 0.1$ & $11.6 \pm 0.9^{f}$ & $3.3 \pm 0.1$ & n.e. & n.e. \\
\hline metformin (MEF) & $66 \pm 2$ & $1.1 \pm 0.1$ & $1.6 \pm 0.0$ & $3.9 \pm 0.2$ & $15.3 \pm 2.2$ & n.e. & n.e. \\
\hline$O$-desmethylvenlafaxine (MLX) & $0 \pm 6^{*}$ & $14.1 \pm 6.8^{\mathrm{f}}$ & $12.1 \pm 5.6^{*}$ & inf & $1.5 \pm 0.2$ & n.e. & n.e. \\
\hline metoprolol acid (MTA) & $-35 \pm 8$ & $2.0 \pm 0.2^{\mathrm{f}}$ & $12.8 \pm 4.7^{\mathrm{f}, *}$ & inf & n.e. & n.e. & n.e. \\
\hline metoprolol (MTP) & $90 \pm 1$ & $0.2 \pm 0.0$ & $1.3 \pm 0.1$ & $2.5 \pm 0.5$ & $4.5 \pm 0.5$ & n.e. & n.e. \\
\hline olmesartan (OLM) & $18 \pm 4$ & $1.5 \pm 0.1$ & inf & inf & $1.4 \pm 0.1$ & $1.3 \pm 0.2$ & n.e. \\
\hline primidone (PRI) & $-18 \pm 7$ & $10.3 \pm 3.9^{\mathrm{f}, *}$ & inf & $11.0 \pm 0.8^{\mathrm{f}, *}$ & $1.4 \pm 0.1$ & n.e. & n.e. \\
\hline sulfamethoxazole (SMX) & $-47 \pm 8$ & $6.8 \pm 1.4^{\mathrm{f}, *}$ & $4.9 \pm 0.4^{\mathrm{f}}$ & $11.1 \pm 1.7^{\mathrm{f}, *}$ & $1.6 \pm 0.2$ & $1.1 \pm 0.1$ & $1.1 \pm 0.1$ \\
\hline sotalol (SOT) & $50 \pm 2$ & $0.8 \pm 0.0$ & $3.3 \pm 0.2$ & $5.8 \pm 0.6^{*}$ & $1.9 \pm 0.2$ & n.e. & n.e. \\
\hline tramadol (TRA) & $12 \pm 4$ & $3.5 \pm 0.2$ & inf & inf & $2.2 \pm 0.2$ & n.e. & n.e. \\
\hline valsartan (VAL) & $26 \pm 4$ & $1.1 \pm 0.0$ & $7.8 \pm 0.2$ & $9.4 \pm 1.1^{\mathrm{f}, *}$ & $1.9 \pm 0.0$ & n.e. & n.e. \\
\hline venlafaxine (VLX) & $-5 \pm 9 *$ & $6.2 \pm 2.2 *$ & inf & $9.0 \pm 5.8^{*}$ & $3.6 \pm 0.6$ & n.e. & n.e. \\
\hline valsartan acid (VSA) & $-205 \pm 15$ & $1.2 \pm 0.0^{\mathrm{f}}$ & $2.4 \pm 0.1^{\mathrm{f}}$ & $7.6 \pm 0.9^{f}$ & $1.1 \pm 0.1$ & $1.0 \pm 0.0$ & n.e. \\
\hline
\end{tabular}



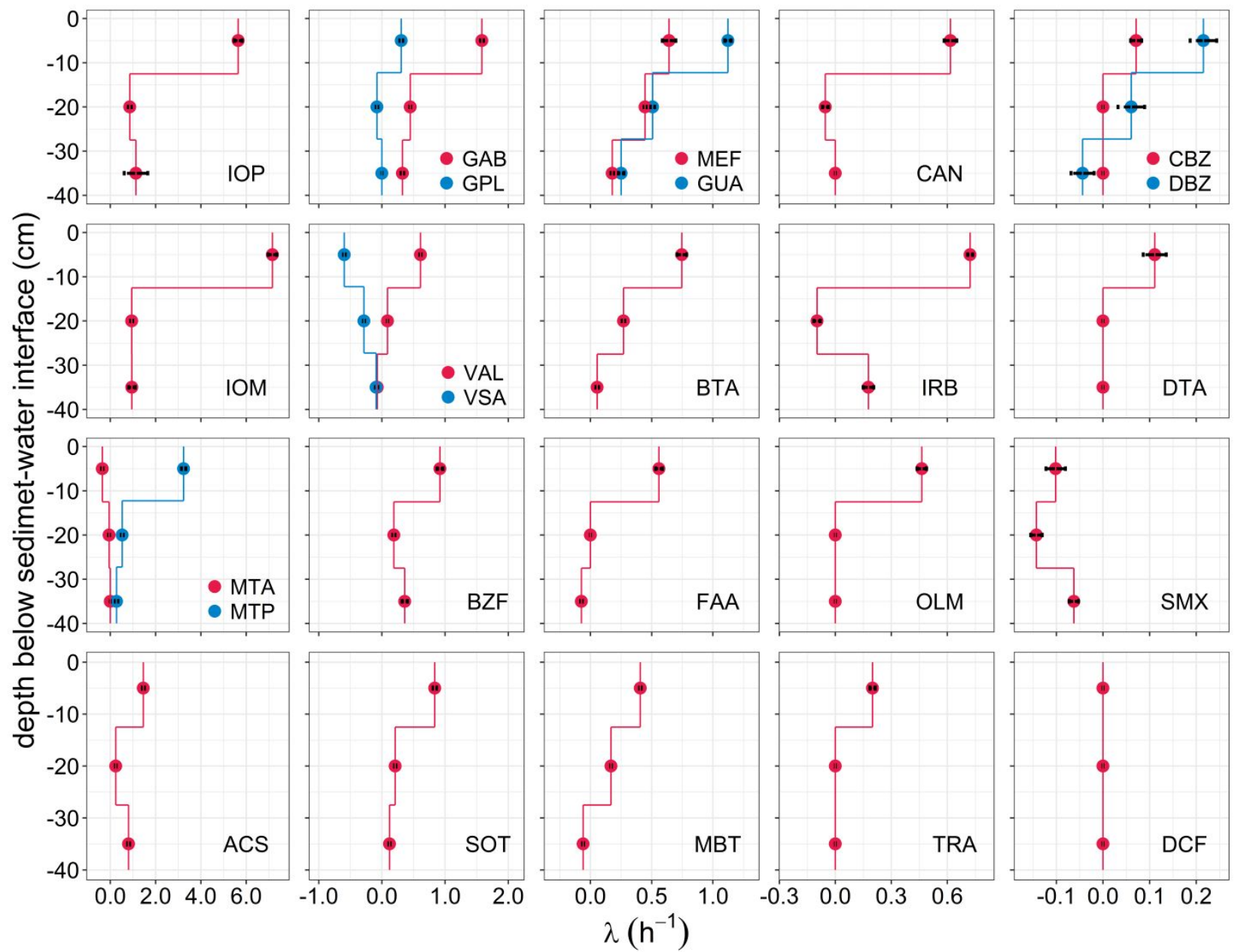

Figure 3 First-order removal rate constants $(\lambda)$ as a function of depth of all investigated parent compounds (PCs, shown in red) and transformation compounds (TPs, shown in blue) except, primidone, epoxy-carbamazepine, venlafaxine and $O$ -

desmethylvenlafaxine. Error bars indicate one standard deviation. ACS, acesulfame; BTA, benzotriazole; BZF, bezafibrate; CAN, candesartan; CBZ, carbamazepine; DBZ, dihydroxy-carbamazepine; DCF, diclofenac; DTA, diatrizoic acid; FAA, 4formylaminoantipyrine; GAB, gabapentin; GPL, gabapentin-lactam; GUA, guanylurea; IOM, iomeprol; IOP, iopromide; IRB, irbesartan; MBT, methylbenzotriazole; MEF, metformin; MTA, metoprolol acid; MTP, metoprolol; olmesartan, OLM; SMX, sulfamethoxazole; SOT, sotalol; TRA, tramadol; VAL, valsartan; VSA, valsartan acid. 


\subsection{Retardation of TrOCs in the $\mathrm{HZ}$}

396 Surface water concentration time series of all 28 TrOCs that were further investigated in the present study 397 showed a pronounced temporal pattern (i.e. a concentration trough) and thus retardation coefficients for all 398 TrOCs except IOP and MTA could be calculated for the first $10 \mathrm{~cm}$ in the HZ. However, concentration 399 time series of many TrOCs measured in 10 and $30 \mathrm{~cm}$ did no longer exhibit a distinct temporal pattern and 400 thus retardation coefficients could not be estimated between $10-30$ and $30-40 \mathrm{~cm}$ for these compounds 401 (Table 2). Calculated retardation coefficients ranged from $1.1 \pm 0.1$ (i.e., no retardation) for compounds 402 such as ACS, VSA, and DTA to $15.3 \pm 2.2$ for MEF (Table 2).

403 Retardation of TrOCs along hyporheic flow paths is due to reversible sorption processes caused by a 404 variety of interaction mechanisms between TrOCs and streambed sediments and biofilms. Neutral TrOCs 405 interact with streambed materials predominately via hydrophobic partitioning, while sorption and 406 retardation of ionizable compounds can additionally be caused by electrostatic interactions and surface 407 complexation. ${ }^{18}$ At ambient $\mathrm{pH}$ values measured in River Erpe during the sampling campaign $(\mathrm{pH} \approx 7.3)$, 4087 of the investigated compounds occur as cations (GUA, MEF, MTP, SOT, VLX, MLX and TRA), 10 409 TrOCs occur as anions (ACS, BZF, CAN, DCF, DTA, IRB, OLM, SMX, VAL and VSA), 2 occur as a 410 zwitterions (GAB, MTA) and 9 do not carry any charge (BTA, CBZ, DBZ, FAA, GPL, IOM, IOP, MBT, 411 and PRI). To assess the possible influence of hydrophobic partitioning retardation, Pearson Product 412 Moment correlations were calculated between retardation coefficients estimated for the first $10 \mathrm{~cm}$ in the $413 \mathrm{HZ}$ and $\mathrm{pH}$-dependent octanol-water partitioning coefficients $\left(\log \mathrm{D}_{\mathrm{ow}}\right)$ of the respective TrOCs (obtained 414 from www.chemicalize.com, Table SI-05). Retardation coefficients of positively charged TrOCs were all 415 larger than 1 and did not significantly correlate with $\log \mathrm{D}_{\mathrm{ow}}$ values (Table SI-06), suggesting that the 416 contribution of hydrophobic partitioning to retardation of cationic TrOCs is negligible. This finding is in 417 line with previous observations indicating that sorption of cationic TrOCs, such as MEF, its TP GUA, ${ }^{63}$ 418 VLX $^{64}$ and beta-blockers such as MTP and SOT ${ }^{13,65}$ to sediment materials can be substantial and occurs 419 predominately via electrostatic interactions. By contrast, $\log \mathrm{D}_{\mathrm{ow}}$ values of negatively charged TrOCs 
420 correlated positively with estimated retardation coefficients (Table SI-06), indicating that retardation of 421 anionic TrOCs in the $\mathrm{HZ}$ is at least partially caused by hydrophobic partitioning into sediment organic 422 matter. This finding is in agreement with work that showed that sorption of anionic compounds is driven 423 by their hydrophobicity rather than by electrostatic interactions. ${ }^{66}$ For the neutral TrOCs PRI, CBZ, and 424 DBZ, retardation coefficients found in a laboratory column $\left(\mathrm{R}_{\mathrm{CBZ}}=2.1, \mathrm{R}_{\mathrm{DBZ}}=3.2, \mathrm{f}_{\mathrm{oc}}=0.29 \%\right)^{20}$ and 425 batch tests $\left(\mathrm{R}_{\mathrm{CBZ}}=3.6-5.3, \mathrm{R}_{\mathrm{PRI}}=1.2, \mathrm{f}_{\mathrm{oc}}=0.23 \%\right)^{21}$ compared well to values calculated in the present 426 study (sediment $\left.\mathrm{f}_{\mathrm{oc}}=0.5-6 \%\right),{ }^{14}$ while a field study had found negligible retardation for compounds such 427 as CBZ and BTA during riparian bank filtration $\left(\mathrm{f}_{\mathrm{oc}}=0.01-0.11 \%\right){ }^{16}$ Such discrepancies are likely 428 attributable to differences in sediment organic matter content and general sediment heterogeneity.

429 We conclude that reversible sorption processes can substantially retard TrOCs along hyporheic flow paths, 430 even for compounds that are negatively charged. Retardation caused by reversible sorption processes 431 increases the residence time of TrOCs relative to the water residence time in the HZ. Neglecting the effect 432 of retardation may lead to erroneous estimates of removal rate constants, particularly when their 433 calculation is based on simple concentration differences ${ }^{17}$ and when sampling periods are relatively short 434 compared to the characteristic time scales over which surface water concentrations fluctuate. Studies that 435 aim at quantitatively investigating the fate of TrOCs in the $\mathrm{HZ}$ and along river reaches with significant 436 hyporheic exchange flows should therefore consider retardation and adjust their reactive transport models 437 and sampling schemes accordingly. Some compounds (e.g. CBZ, DBZ, VLX, or DCF) were retarded 438 along the investigated hyporheic flow path but showed only very small removal rates in the HZ. If 439 concentrations of these compounds in surface waters drop considerably over short time scales (e.g. during 440 hydrological events), desorption processes might remobilize TrOCs previously adsorbed to sediment 441 materials and biofilms and hence hyporheic exchange would lead to a concentration increase of these 442 TrOCs in the surface water. 


\section{$444 \quad 3.5$ Influence of benthic bio-layer and DOC on TrOC reactivity}

445 For all TrOCs for which concentration changed significantly between the surface water and $40 \mathrm{~cm}$ depth 446 in the HZ (22 out of 28) except SMX, removal rates calculated for the top $10 \mathrm{~cm}$ in the $\mathrm{HZ}$ were 447 substantially higher compared to removal rate constants calculated between 10 and 30 and 30 and $40 \mathrm{~cm}$ 448 depth (Figure 3). Because redox conditions in the top $30 \mathrm{~cm}$ of the $\mathrm{HZ}$ were predominantly oxic, it is 449 reasonable to assume that the increased reactivity in the top $10 \mathrm{~cm}$ of the $\mathrm{HZ}$ is due to increased microbial 450 activity in the benthic bio-layers growing in the top $\mathrm{cm}$ of the $\mathrm{HZ}$ and high chemical turnover rates 451 typically associated with shallow hyporheic flow paths. ${ }^{10,11}$ This finding is further underlined by changes 452 in DOC concentration and quality, suggesting that TrOC turnover within similar redox zones in the HZ is 453 closely coupled to DOC turnover. Studies on managed aquifer recharge reported that TrOC removal rates 454 under oxic conditions were highest when BDOC was limited, an observation that was mainly attributed to 455 the presence of highly adapted microbial communities that developed under oligotrophic conditions..$^{22,49,67}$ 456 However, our results show, that in natural systems such as the HZ, high TrOC removal rates can also be 457 associated with oxic and eutrophic conditions, in which high concentrations of BDOC likely fuel 458 microbial metabolism and serve as a co-substrate for the co-metabolic removal of TrOCs.

459 Due to practical limitations associated with our sampling approach, the present study investigated a 460 downwelling flow path that is unlikely to return to the surface water. However, our findings should in 461 principle be transferable to hyporheic flow paths that return to the stream and thus have implications for 462 reach-scale removal of TrOCs. Together with earlier investigations showing that for many TrOCs removal 463 rates are higher under oxic compared to anoxic redox conditions, ${ }^{12,14}$ our results suggest that short and 464 shallow flow paths are more efficient in removing TrOCs than long and deep flow paths, along which 465 redox conditions become increasingly anoxic and microbial activity decreases. River restoration measures 466 that promote frequent and short vertical exchange flows through the shallow HZ, such as the construction 467 of engineered hyporheic zone elements ${ }^{68-70}$ or the application of woody debris, ${ }^{71}$ are therefore likely to 
468 contribute more to overall in-stream removal of TrOCs than measures that promote, longer lateral 469 exchange flows such as the installation of meander bends or pool-riffle sequences.

470 


\section{References}

(1) Ternes, T. A.; Joss, A.; Siegrist, H. Peer Reviewed: Scrutinizing Pharmaceuticals and Personal Care Products in Wastewater Treatment. Environ. Sci. Technol. 2004, 38 (20), 392A-399A. https://doi.org/10.1021/es040639t.

(2) Eggen, R. I. L.; Hollender, J.; Joss, A.; Schärer, M.; Stamm, C. Reducing the Discharge of Micropollutants in the Aquatic Environment: The Benefits of Upgrading Wastewater Treatment Plants. Environ. Sci. Technol. 2014, 48 (14), 7683-7689. https://doi.org/10.1021/es500907n.

(3) Bradley, P. M.; Journey, C. A.; Romanok, K. M.; Barber, L. B.; Buxton, H. T.; Foreman, W. T.; Furlong, E. T.; Glassmeyer, S. T.; Hladik, M. L.; Iwanowicz, L. R.; Jones, D. K.; Kolpin, D. W.; Kuivila, K. M.; Loftin, K. A.; Mills, M. A.; Meyer, M. T.; Orlando, J. L.; Reilly, T. J.; Smalling, K. L.; Villeneuve, D. L. Expanded Target-Chemical Analysis Reveals Extensive Mixed-OrganicContaminant Exposure in U.S. Streams. Environ. Sci. Technol. 2017, 51 (9), 4792-4802. https://doi.org/10.1021/acs.est.7b00012.

(4) Loos, R.; Carvalho, R.; António, D. C.; Comero, S.; Locoro, G.; Tavazzi, S.; Paracchini, B.; Ghiani, M.; Lettieri, T.; Blaha, L.; Jarosova, B.; Voorspoels, S.; Servaes, K.; Haglund, P.; Fick, J.; Lindberg, R. H.; Schwesig, D.; Gawlik, B. M. EU-Wide Monitoring Survey on Emerging Polar Organic Contaminants in Wastewater Treatment Plant Effluents. Water Res. 2013, 47 (17), 64756487. https://doi.org/10.1016/j.watres.2013.08.024.

(5) Brodin, T.; Fick, J.; Jonsson, M.; Klaminder, J. Dilute Concentrations of a Psychiatric Drug Alter Behavior of Fish from Natural Populations. Science 2013, 339 (6121), 814-815. https://doi.org/10.1126/science.1226850.

(6) Schwarzenbach, R. P.; Egli, T.; Hofstetter, T. B.; von Gunten, U.; Wehrli, B. Global Water Pollution and Human Health. Annu. Rev. Environ. Resour. 2010, 35 (1), 109-136. https://doi.org/10.1146/annurev-environ-100809-125342.

(7) Arnnok, P.; Singh, R. R.; Burakham, R.; Pérez-Fuentetaja, A.; Aga, D. S. Selective Uptake and 
Bioaccumulation of Antidepressants in Fish from Effluent-Impacted Niagara River. Environ. Sci. Technol. 2017, 51 (18), 10652-10662. https://doi.org/10.1021/acs.est.7b02912.

Pal, A.; He, Y.; Jekel, M.; Reinhard, M.; Gin, K. Y. H. Emerging Contaminants of Public Health Significance as Water Quality Indicator Compounds in the Urban Water Cycle. Environment International. 2014, 71, 46-62. https://doi.org/10.1016/j.envint.2014.05.025.

(10) Knapp, J. L. A.; González-Pinzón, R.; Drummond, J. D.; Larsen, L. G.; Cirpka, O. A.; Harvey, J.

(11) Krause, S.; Lewandowski, J.; Grimm, N. B.; Hannah, D. M.; Pinay, G.; McDonald, K.; Martí, E.;

Argerich, A.; Pfister, L.; Klaus, J.; Battin, T.; Larned, S. T.; Schelker, J.; Fleckenstein, J.; Schmidt,

C.; Rivett, M. O.; Watts, G.; Sabater, F.; Sorolla, A.; Turk, V. Ecohydrological Interfaces as Hot Spots of Ecosystem Processes. Water Resour. Res. 2017, 53 (8), 6359-6376. https://doi.org/10.1002/2016WR019516. 
https://doi.org/10.1016/j.watres.2018.04.040.

(15) Lewandowski, J.; Putschew, A.; Schwesig, D.; Neumann, C.; Radke, M. Fate of Organic Micropollutants in the Hyporheic Zone of a Eutrophic Lowland Stream: Results of a Preliminary Field Study. Sci. Total Environ. 2011, $409 \quad$ (10), 1824-1835. https://doi.org/10.1016/j.scitotenv.2011.01.028.

(16) Huntscha, S.; Rodriguez Velosa, D. M.; Schroth, M. H.; Hollender, J. Degradation of Polar Organic Micropollutants during Riverbank Filtration: Complementary Results from Spatiotemporal Sampling and Push-Pull Tests. Environ. Sci. Technol. 2013, 47 (20), 11512-11521. https://doi.org/10.1021/es401802z.

(17) Schaper, J. L.; Posselt, M.; Mccallum, J. L.; Banks, E.; Hoehne, A.; Meinikmann, K.; Shanafield, M.; Batelaan, O.; Lewandowski, J. Hyporheic Exchange Controls Fate of Trace Organic Compounds in an Urban Stream. Environ. Sci. Technol. 2018, 52, 12285-12294. https://doi.org/10.1021/acs.est.8b03117.

(18) MacKay, A. A.; Vasudevan, D. Polyfunctional Ionogenic Compound Sorption: Challenges and New Approaches to Advance Predictive Models. Environ. Sci. Technol. 2012, 46 (17), 9209-9223. https://doi.org/10.1021/es301036t.

(19) Schaffer, M.; Börnick, H.; Nödler, K.; Licha, T.; Worch, E. Role of Cation Exchange Processes on the Sorption Influenced Transport of Cationic $\beta$-Blockers in Aquifer Sediments. Water Res. 2012, 46 (17), 5472-5482. https://doi.org/10.1016/j.watres.2012.07.013.

(20) Writer, J. H.; Antweiler, R. C.; Ferrer, I.; Ryan, J. N.; Thurman, E. M. In-Stream Attenuation of Neuro-Active Pharmaceuticals and Their Metabolites. Environ. Sci. Technol. 2013, 47 (17), 97819790. https://doi.org/10.1021/es402158t.

(21) Schaffer, M.; Boxberger, N.; Börnick, H.; Licha, T.; Worch, E. Sorption Influenced Transport of Ionizable Pharmaceuticals onto a Natural Sandy Aquifer Sediment at Different PH. Chemosphere 2012, 87 (5), 513-520. https://doi.org/10.1016/j.chemosphere.2011.12.053. 
546

(22) Rauch-Williams, T.; Hoppe-Jones, C.; Drewes, J. E. The Role of Organic Matter in the Removal of Emerging Trace Organic Chemicals during Managed Aquifer Recharge. Water Res. 2010, 44 (2), 449-460. https://doi.org/10.1016/j.watres.2009.08.027.

(23) Harvey, J. W.; Böhlke, J. K.; Voytek, M. A.; Scott, D.; Tobias, C. R. Hyporheic Zone Denitrification: Controls on Effective Reaction Depth and Contribution to Whole-Stream Mass Balance. Water Resour. Res. 2013, 49 (10), 6298-6316. https://doi.org/10.1002/wrcr.20492.

(24) Peralta-Maraver, I.; Galloway, J.; Posselt, M.; Arnon, S.; Reiss, J.; Lewandowski, J.; Robertson, A. L. Environmental Filtering and Community Delineation in the Streambed Ecotone. Sci. Rep. 2018, 8 (October 2017), 1-11. https://doi.org/10.1038/s41598-018-34206-z.

(25) Kunkel, U.; Radke, M. Fate of Pharmaceuticals in Rivers: Deriving a Benchmark Dataset at Favorable Attenuation Conditions. Water Res. 2012, 46 (17), 5551-5565. https://doi.org/10.1016/j.watres.2012.07.033.

(26) Posselt, M.; Jaeger, A.; Schaper, J. L.; Radke, M.; Benskin, J. P. Determination of Polar Organic Micropollutants in Surface and Pore Water by High-Resolution Sampling-Direct Injection-Ultra High Performance Liquid Chromatography-Tandem Mass Spectrometry. Environ. Sci. Process. Impacts 2018, 20 (12), 1716-1727. https://doi.org/10.1039/c8em00390d.

(27) Munz, M.; Oswald, S. E.; Schmidt, C. Analysis of Riverbed Temperatures to Determine the Geometry of Subsurface Water Flow around In-Stream Geomorphological Structures. J. Hydrol. 2016, 539, 74-87. https://doi.org/10.1016/j.jhydrol.2016.05.012.

(28) McCallum, A. M.; Andersen, M. S.; Rau, G. C.; Acworth, R. I. A 1-D Analytical Method for Estimating Surface Water-Groundwater Interactions and Effective Thermal Diffusivity Using Temperature Time Series. Water Resour. Res. 2012, $48 \quad$ (11), 1-8. https://doi.org/10.1029/2012WR012007.

(29) Gordon, R. P.; Lautz, L. K.; Briggs, M. A.; McKenzie, J. M. Automated Calculation of Vertical Pore-Water Flux from Field Temperature Time Series Using the VFLUX Method and Computer 
Program. J. Hydrol. 2012, 420-421, 142-158. https://doi.org/10.1016/j.jhydrol.2011.11.053.

(30) Young, P. C.; Pedregal, D. J.; Tych, W. Dynamic Harmonic Regression. J. Forecast. 1999, 18 (6), 369-394. https://doi.org/10.1002/(SICI)1099-131X(199911)18:6<369::AID-FOR748>3.0.CO;2-K.

(31) Jaeger, A.; Posselt, M.; Betterle, A.; Schaper, J.; Mechelke, J.; Coll, C.; Lewandowski, J. Spatial and Temporal Variability in Attenuation of Polar Organic Micropollutants in an Urban Lowland Stream. Environ. Sci. Technol. 2018, 53, 2383-2395. https://doi.org/10.1021/acs.est.8b05488.

(32) Zietzschmann, F.; Aschermann, G.; Jekel, M. Comparing and Modeling Organic Micro-Pollutant Adsorption onto Powdered Activated Carbon in Different Drinking Waters and WWTP Effluents. Water Res. 2016, 102, 190-201. https://doi.org/10.1016/j.watres.2016.06.041.

(33) Aschermann, G.; Zietzschmann, F.; Jekel, M. Influence of Dissolved Organic Matter and Activated Carbon Pore Characteristics on Organic Micropollutant Desorption. Water Res. 2018, 133, 123131. https://doi.org/10.1016/j.watres.2018.01.015.

(34) Ohno, T. Fluorescence Inner-Filtering Correction for Determining the Humification Index of Dissolved Organic Matter. Environ. Sci. Technol. 2002, 36 (4), 742-746. https://doi.org/10.1021/es0155276.

(35) Weishaar, J. L.; Aiken, G. R.; Bergamaschi, B. A.; Fram, M. S.; Fujii, R.; Mopper, K. Evaluation of Specific Ultraviolet Absorbance as an Indicator of the Chemical Composition and Reactivity of Dissolved Organic Carbon. Environ. Sci. Technol. 2003, 37 (20), 4702-4708. https://doi.org/10.1021/es030360x.

(36) Harvey, R. W.; Garabedian, S. P. Use of Colloid Filtration Theory in Modelling Movement of Bacteria through a Contaminated Sandy Aquifer. Environ. Sci. Technol. 1991, 25, 178-185.

(37) Kunkel, U.; Radke, M. Reactive Tracer Test to Evaluate the Fate of Pharmaceuticals in Rivers. Environ. Sci. Technol. 2011, 45 (15), 6296-6302. https://doi.org/10.1021/es104320n.

(38) Vrugt, J. A.; Robinson, B. A.; Clark, M. P.; ter Braak, C. J. F.; Hyman, J. M. Treatment of Input Uncertainty in Hydrologic Modeling: Doing Hydrology Backward with Markov Chain Monte 
Carlo Simulation. Water Resour. Res. 2008, 44 (12), 1-15. https://doi.org/10.1029/2007wr006720.

597

598

599

600

601

602

603

(39) Vrugt, J. A. Markov Chain Monte Carlo Simulation Using the DREAM Software Package: Theory, Concepts, and MATLAB Implementation. Environ. Model. Softw. 2016, 75, 273-316. https://doi.org/10.1016/j.envsoft.2015.08.013.

(40) Voermans, J. J.; Ghisalberti, M.; Ivey, G. N. A Model for Mass Transport Across the SedimentWater Interface. Water Resour. Res. 2018, $54 \quad$ (4), 2799-2812. https://doi.org/10.1002/2017WR022418.

(41) Grant, S. B.; Azizian, M.; Cook, P.; Boano, F.; Rippy, M. A. Factoring Stream Turbulence into Global Assessments of Nitrogen Pollution. Science 2018, 359, 1266-1269.

(42) Zarnetske, J. P.; Haggerty, R.; Wondzell, S. M.; Baker, M. A. Dynamics of Nitrate Production and Removal as a Function of Residence Time in the Hyporheic Zone. J. Geophys. Res. Biogeosciences 2011, 116 (1), 1-12. https://doi.org/10.1029/2010JG001356.

(43) Mulholland, P. J.; Helton, A. M.; Poole, G. C.; Hall, R. O.; Hamilton, S. K.; Peterson, B. J.; Tank, J. L.; Ashkenas, L. R.; Cooper, L. W.; Dahm, C. N.; Dodds, W. K.; Findlay, S. E. G.; Gregory, S. V.; Grimm, N. B.; Johnson, S. L.; McDowell, W. H.; Meyer, J. L.; Valett, H. M.; Webster, J. R.; Arango, C. P.; Beaulieu, J. J.; Bernot, M. J.; Burgin, A. J.; Crenshaw, C. L.; Johnson, L. T.; Niederlehner, B. R.; O’Brien, J. M.; Potter, J. D.; Sheibley, R. W.; Sobota, D. J.; Thomas, S. M. Stream Denitrification across Biomes and Its Response to Anthropogenic Nitrate Loading. Nature 2008, 452 (7184), 202-205. https://doi.org/10.1038/nature06686.

(44) Briggs, M. A.; Day-Lewis, F. D.; Zarnetske, J. P.; Harvey, J. W. A Physical Explanation for the Development of Redox Microzones in Hyporheic Flow. Geophys. Res. Lett. 2015, 42 (11), 44024410. https://doi.org/10.1002/2015GL064200.

(45) Redeker, M.; Wick, A.; Meermann, B.; Ternes, T. A. Anaerobic Transformation of the Iodinated X-Ray Contrast Medium Iopromide, Its Aerobic Transformation Products, and Transfer to Further Iodinated X-Ray Contrast Media. Environ. Sci. Technol. 2018, 52, 8309-8320. 
https://doi.org/10.1021/acs.est.8b01140.

(46) Schulz, M.; Löffler, D.; Wagner, M.; Ternes, T. A. Transformation of the X-Ray Contrast Medium Iopromide in Soil and Biological Wastewater Treatment. Environ. Sci. Technol. 2008, 42 (19), 7207-7217. https://doi.org/10.1021/es800789r.

(47) Kormos, J. L.; Schulz, M.; Kohler, H. P. E.; Ternes, T. A. Biotransformation of Selected Iodinated X-Ray Contrast Media and Characterization of Microbial Transformation Pathways. Environ. Sci. Technol. 2010, 44 (13), 4998-5007. https://doi.org/10.1021/es1007214.

(48) Henning, N.; Kunkel, U.; Wick, A.; Ternes, T. A. Biotransformation of Gabapentin in Surface Water Matrices under Different Redox Conditions and the Occurrence of One Major TP in the Aquatic Environment. Water Res. 2018, 137, 290-300. https://doi.org/10.1016/j.watres.2018.01.027.

(49) Hellauer, K.; Karakurt, S.; Sperlich, A.; Burke, V.; Massmann, G.; Hübner, U.; Drewes, J. E. Establishing Sequential Managed Aquifer Recharge Technology (SMART) for Enhanced Removal of Trace Organic Chemicals: Experiences from Field Studies in Berlin, Germany. J. Hydrol. 2018, 563, 1161-1168. https://doi.org/10.1016/j.jhydrol.2017.09.044.

(50) Trautwein, C.; Kümmerer, K. Incomplete Aerobic Degradation of the Antidiabetic Drug Metformin and Identification of the Bacterial Dead-End Transformation Product Guanylurea. Chemosphere 2011, 85 (5), 765-773. https://doi.org/10.1016/j.chemosphere.2011.06.057.

(51) Trautwein, C.; Berset, J. D.; Wolschke, H.; Kümmerer, K. Occurrence of the Antidiabetic Drug Metformin and Its Ultimate Transformation Product Guanylurea in Several Compartments of the Aquatic Cycle. Environ. Int. 2014, 70, 203-212. https://doi.org/10.1016/j.envint.2014.05.008.

(52) Bradley, P. M.; Journey, C. A.; Button, D. T.; Carlisle, D. M.; Clark, J. M.; Mahler, B. J.; Nakagaki, N.; Qi, S. L.; Waite, I. R.; VanMetre, P. C. Metformin and Other Pharmaceuticals Widespread in Wadeable Streams of the Southeastern United States. Environ. Sci. Technol. Lett. 2016, 3 (6), 243-249. https://doi.org/10.1021/acs.estlett.6b00170. 
646
(53) Scheurer, M.; Michel, A.; Brauch, H. J.; Ruck, W.; Sacher, F. Occurrence and Fate of the Antidiabetic Drug Metformin and Its Metabolite Guanylurea in the Environment and during Drinking Water Treatment. Water Res. 2012, $46 \quad$ (15), 4790-4802. https://doi.org/10.1016/j.watres.2012.06.019.

(54) Letzel, T.; Bayer, A.; Schulz, W.; Heermann, A.; Lucke, T.; Greco, G.; Grosse, S.; Schüssler, W.; Sengl, M.; Letzel, M. LC-MS Screening Techniques for Wastewater Analysis and Analytical Data Handling Strategies: Sartans and Their Transformation Products as an Example. Chemosphere 2015, 137, 198-206. https://doi.org/10.1016/j.chemosphere.2015.06.083.

(55) Nödler, K.; Hillebrand, O.; Idzik, K.; Strathmann, M.; Schiperski, F.; Zirlewagen, J.; Licha, T. Occurrence and Fate of the Angiotensin II Receptor Antagonist Transformation Product Valsartan Acid in the Water Cycle - A Comparative Study with Selected $\beta$-Blockers and the Persistent Anthropogenic Wastewater Indicators Carbamazepine and Acesulfame. Water Res. 2013, 47 (17), 6650-6659. https://doi.org/10.1016/j.watres.2013.08.034.

(56) Bertelkamp, C.; Reungoat, J.; Cornelissen, E. R.; Singhal, N.; Reynisson, J.; Cabo, A. J.; van der Hoek, J. P.; Verliefde, A. R. D. Sorption and Biodegradation of Organic Micropollutants during River Bank Filtration: A Laboratory Column Study. Water Res. 2014, 52, 231-241. https://doi.org/10.1016/j.watres.2013.10.068.

(57) Wiese, B.; Massmann, G.; Jekel, M.; Heberer, T.; Dünnbier, U.; Orlikowski, D.; Grützmacher, G. Removal Kinetics of Organic Compounds and Sum Parameters under Field Conditions for Managed Aquifer Recharge. Water Res. 2011, $45 \quad$ (16), 4939-4950. https://doi.org/10.1016/j.watres.2011.06.040.

(58) Hellauer, K.; Mergel, D.; Ruhl, A. S.; Filter, J.; Hübner, U.; Jekel, M.; Drewes, J. E. Advancing Sequential Managed Aquifer Recharge Technology (SMART) Using Different Intermediate Oxidation Processes. Water 2017, 9 (221), 1-14. https://doi.org/10.3390/w9030221.

(59) Redeker, M.; Wick, A.; Meermann, B.; Ternes, T. A. Removal of the Iodinated X-Ray Contrast 35 
Medium Diatrizoate by Anaerobic Transformation. Environ. Sci. Technol. 2014, 48 (17), 1014510154. https://doi.org/10.1021/es5014714.

(60) Su, T.; Deng, H.; Benskin, J. P.; Radke, M. Biodegradation of Sulfamethoxazole PhotoTransformation Products in a Water/Sediment Test. Chemosphere 2016, 148, 518-525. https://doi.org/10.1016/j.chemosphere.2016.01.049.

(61) Zuehlke, S.; Duennbier, U.; Heberer, T. Investigation of the Behavior and Metabolism of Pharmaceutical Residues during Purification of Contaminated Ground Water Used for Drinking Water Supply. Chemosphere 2007, $69 \quad$ (11), 1673-1680. https://doi.org/10.1016/j.chemosphere.2007.06.020.

(62) Massmann, G.; Dünnbier, U.; Heberer, T.; Taute, T. Behaviour and Redox Sensitivity of Pharmaceutical Residues during Bank Filtration - Investigation of Residues of Phenazone-Type Analgesics. $\quad$ Chemosphere $\quad 71 \quad$ 2008, $\quad 1476-1485$. https://doi.org/10.1016/j.chemosphere.2007.12.017.

(63) Briones, R. M.; Sarmah, A. K. Insight into the Sorption Mechanism of Metformin and Its Transformation Product Guanylurea in Pastoral Soils and Model Sorbents. Sci. Total Environ. 2018, 645, 1323-1333. https://doi.org/10.1016/j.scitotenv.2018.07.251.

(64) Torresi, E.; Polesel, F.; Bester, K.; Christensson, M.; Smets, B. F.; Trapp, S.; Andersen, H. R.; Plósz, B. G. Diffusion and Sorption of Organic Micropollutants in Biofilms with Varying Thicknesses. Water Res. 2017, 123, 388-400. https://doi.org/10.1016/j.watres.2017.06.027.

(65) Ramil, M.; El Aref, T.; Fink, G.; Scheurer, M.; Ternes, T. A. Fate of Beta Blockers in AquaticSediment Systems: Sorption and Biotransformation. Environ. Sci. Technol. 2010, 44 (3), 962-970. https://doi.org/10.1021/es9027452.

(66) Tülp, H. C.; Fenner, K.; Schwarzenbach, R. P.; Goss, K. U. PH-Dependent Sorption of Acidic Organic Chemicals to Soil Organic Matter. Environ. Sci. Technol. 2009, 43 (24), 9189-9195. https://doi.org/10.1021/es902272j. 
696

697

698

699

700

701

702

703
(67) Hoppe-Jones, C.; Dickenson, E. R. V.; Drewes, J. E. The Role of Microbial Adaptation and Biodegradable Dissolved Organic Carbon on the Attenuation of Trace Organic Chemicals during Groundwater Recharge. Sci. Total Environ. 2012, 437, 137-144. https://doi.org/10.1016/j.scitotenv.2012.08.009.

(68) Herzog, S. P.; Higgins, C. P.; McCray, J. E. Engineered Streambeds for Induced Hyporheic Flow: Enhanced Removal of Nutrients, Pathogens, and Metals from Urban Streams. J. Environ. Eng. 2016, 142 (1), 04015053. https://doi.org/10.1061/(ASCE)EE.1943-7870.0001012.

(69) Herzog, S. P.; Higgins, C. P.; Singha, K.; McCray, J. E. Performance of Engineered Streambeds for Inducing Hyporheic Transient Storage and Attenuation of Resazurin. Environ. Sci. Technol. 2018, 52 (18), 10627-10636. https://doi.org/10.1021/acs.est.8b01145.

(70) Peter, K. T.; Herzog, S.; Tian, Z.; Wu, C.; McCray, J. E.; Lynch, K.; Kolodziej, E. P. Evaluating Emerging Organic Contaminant Removal in an Engineered Hyporheic Zone Using High Resolution Mass Spectrometry. Water Res. 2019, 150, 140-152. https://doi.org/10.1016/j.watres.2018.11.050.

(71) Blaen, P. J.; Kurz, M. J.; Drummond, J. D.; Knapp, J. L. A.; Mendoza-Lera, C.; Schmadel, N. M.; Klaar, M. J.; Jäger, A.; Folegot, S.; Lee-Cullin, J.; Ward, A. S.; Zarnetske, J. P.; Datry, T.; Milner, A. M.; Lewandowski, J.; Hannah, D. M.; Krause, S. Woody Debris Is Related to Reach-Scale Hotspots of Lowland Stream Ecosystem Respiration under Baseflow Conditions. Ecohydrology 2018, 11 (5), 1-9. https://doi.org/10.1002/eco.1952. 


\section{Supporting Information}

720 (1) Additional information on VFLUX 2.0 calculations and (2) TrOC analysis (Tables SI-01 \& 02); (3)

721 Description of the reactive transport model, DREAM settings, and molecular diffusion coefficients of

722 TrOCs (Table SI-03); (4) Comparison of table reference compounds (Figure SI-01); (5) Median

723 concentrations of TrOCs, $\mathrm{NO}_{3}^{-}-\mathrm{N}$, dissolved manganese and total dissolved iron in the surface water and

724 in hyporheic porewater; (6) Measured hyporheic temperatures (Figure SI-02) and further discussion on

725 DOC and $\mathrm{NO}_{3}^{-}-\mathrm{N}$ dynamics in the $\mathrm{HZ}$ (Figures SI-03 \& 04); (7) pKa and $\mathrm{LogK}_{\mathrm{ow}}$ values of investigated

726 TrOCs (Table SI-05); (8) Pearson Product Moment correlations between $\log \mathrm{D}_{\mathrm{ow}}$ and calculated retardation

727 coefficients; (9) Concentration time series and associated model fits (Figures SI-05 - SI-32) of all 728 investigated TrOCs.

729

730

731

732 


\section{Acknowledgements}

734 This project has been conducted within the Research Training Group 'Urban Water Interfaces (UWI)'

735 (Project N6 "Retention of chemical compounds in hyporheic reactors of urban freshwater systems", GRK

736 2032/1), which is funded by the German Research Foundation (DFG). This project has also received

737 funding from the European Union's Horizon 2020 research and innovation programme under grant

738 agreement No. 641939 (HypoTRAIN). We are grateful to three anonymous reviewers and the editor for

739 discussion and comments on earlier versions of this manuscript.

740 


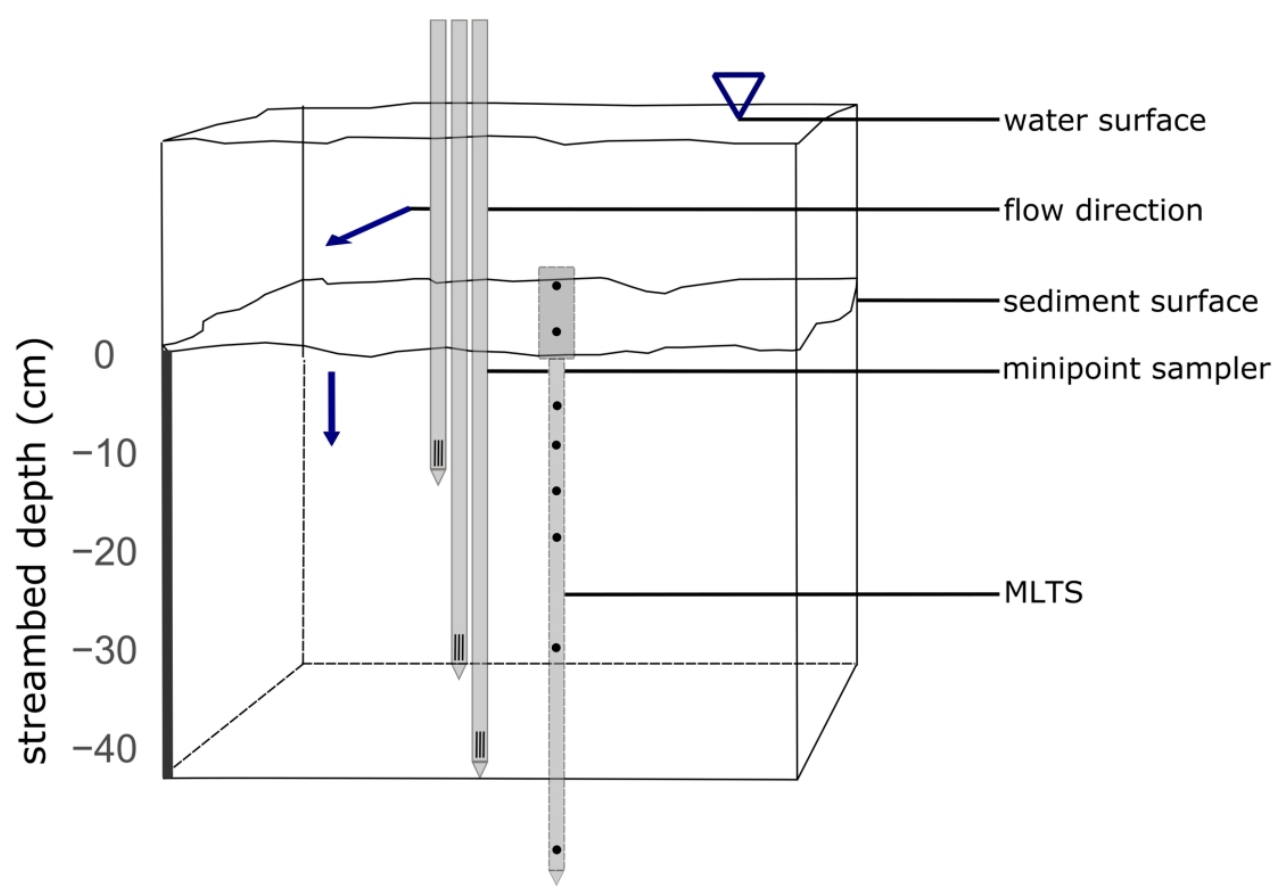

Figure 1 Experimental setup showing the three minipoint sampler installed in $10 \mathrm{~cm}, 30 \mathrm{~cm}$ and $40 \mathrm{~cm}$ depth in the hyporheic zone $(\mathrm{HZ})$. The samplers were installed in a line $(<1 \mathrm{~cm}$ distance) perpendicular to the water flow direction. A Multilevel Temperature Stick (MLTS) was installed in close proximity $(\approx 10 \mathrm{~cm})$ next to the minipoint sampler array. Blue arrows indicate surface water and predominant hyporheic flow directions. Minipoint samplers were sampled from an aluminum bridge spanning the river channel (not shown).

$200 \times 139 \mathrm{~mm}(300 \times 300 \mathrm{DPI})$ 

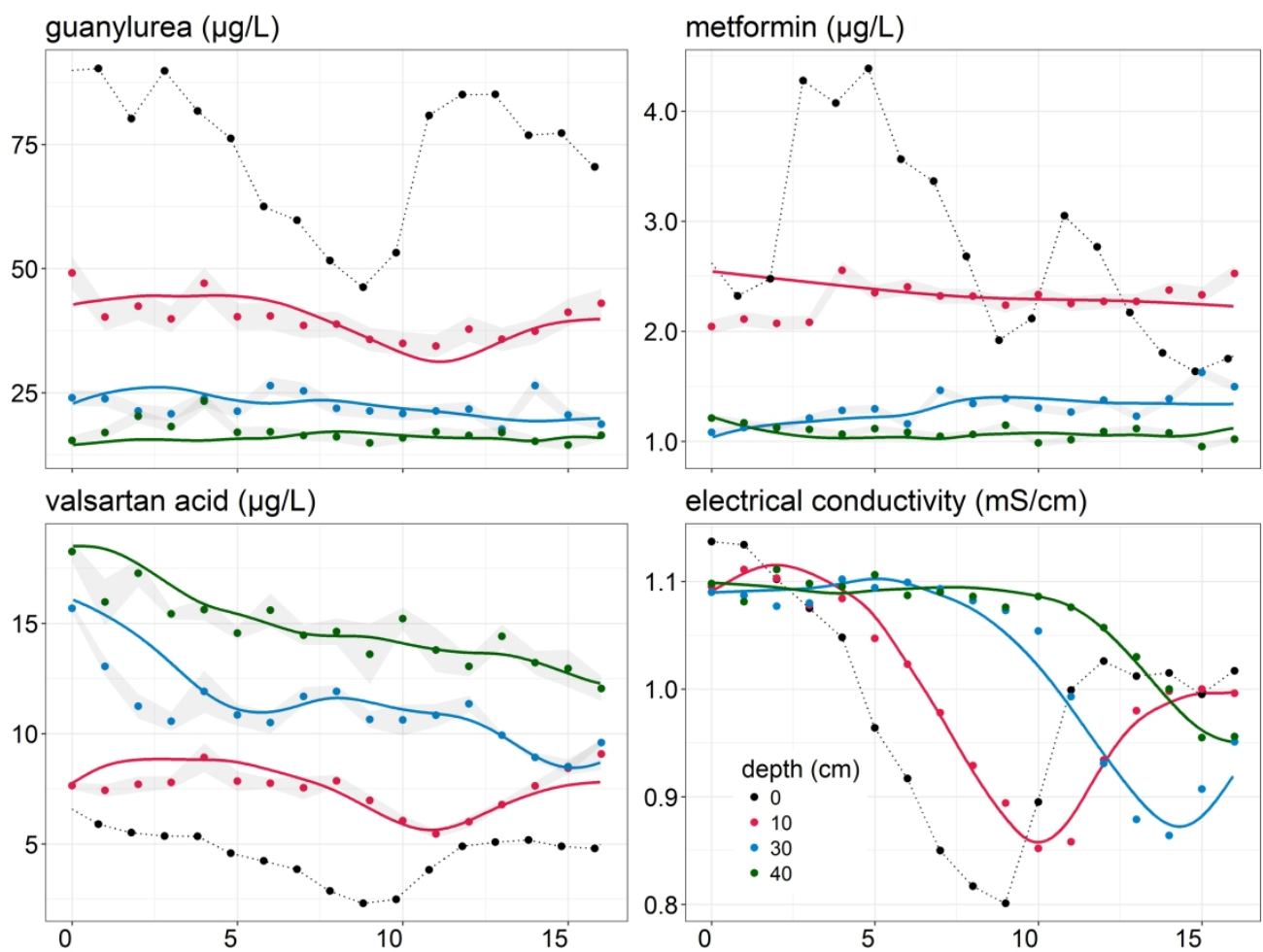

electrical conductivity $(\mathrm{mS} / \mathrm{cm})$

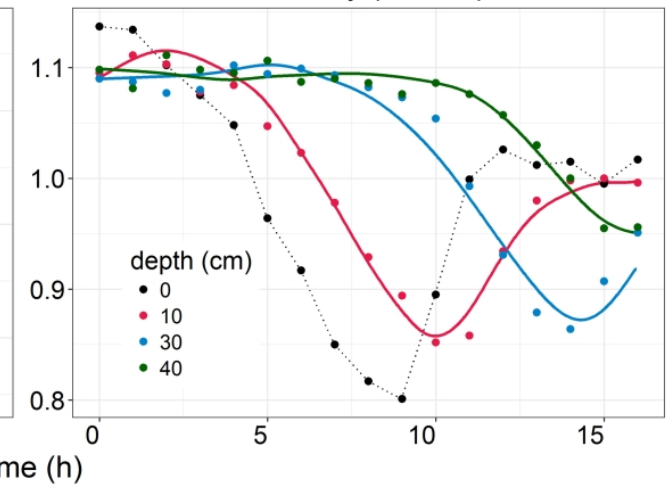

Measured (dots) and modeled (solid lines) concentration time series in $10 \mathrm{~cm}, 30 \mathrm{~cm}$ and $40 \mathrm{~cm}$ depth in the hyporheic zone $(\mathrm{HZ})$ and measured concentration time series in the surface water $(0 \mathrm{~cm})$ of guanylurea (GUA), metformin (MEF), valsartan acid (VSA) and electrical conductivity (EC). For concentration time series measured in the $\mathrm{HZ}$, analytical uncertainty (one standard deviation) is shown in grey. Note that for modeling purposes, concentration time series in the surface water were linearly interpolated (black dashed line) and that for EC no measurement uncertainties were available.

$304 \times 243 \mathrm{~mm}(300 \times 300$ DPI $)$ 

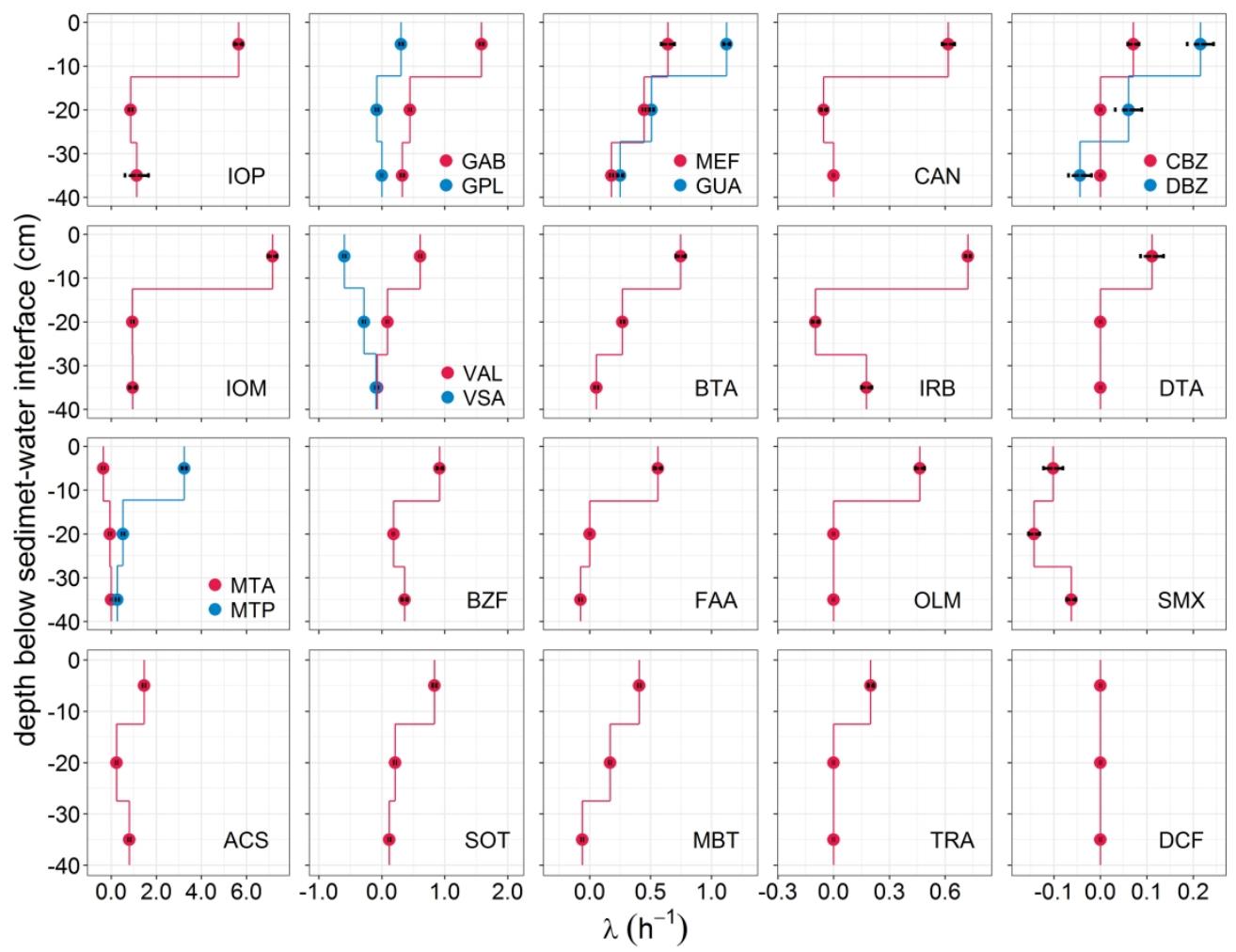

First-order removal rate constants $(\lambda)$ as a function of depth of all investigated parent compounds (PCs, shown in red) and transformation compounds (TPs, shown in blue) except, primidone, epoxycarbamazepine, venlafaxine and O-desmethylvenlafaxine. Error bars indicate one standard deviation. ACS, acesulfame; BTA, benzotriazole; BZF, bezafibrate; CAN, candesartan; CBZ, carbamazepine; DBZ, dihydroxycarbamazepine; DCF, diclofenac; DTA, diatrizoic acid; FAA, 4-formylaminoantipyrine; GAB, gabapentin; GPL, gabapentin-lactam; GUA, guanylurea; IOM, iomeprol; IOP, iopromide; IRB, irbesartan; MBT,

methylbenzotriazole; MEF, metformin; MTA, metoprolol acid; MTP, metoprolol; olmesartan, OLM; SMX, sulfamethoxazole; SOT, sotalol; TRA, tramadol; VAL, valsartan; VSA, valsartan acid.

$304 \times 243 \mathrm{~mm}(300 \times 300$ DPI $)$ 